\title{
Teorias de desarrollo industrial regional y políticas de segunda y tercera generación
}

\author{
A. H. J. (Bert) Helmsing ${ }^{1}$
}

\begin{abstract}
This article observes that the conceptual bases for regional industrial policies has been undergoing substantial changes. A distinction is made between several generations of policies. The 'first generation' of regional policies was based on the importance of exogenous growth factors. The 'second generation' of policies focussed on local endogenous factors. The theoretical base supporting these policies received strong impulses since the mid-80s from new insights derived from flexible specialization and industrial districts literature. A new and 'third generation' of policies is emerging that goes beyond endogenous growth, and seeks to superceed the division between exogenous and endogenously oriented policies. The analysis of growth and competitiveness has moved from the firm itself, and clusters of firms and to incorporate basic and institutional conditions fostering growth. This article provides an overview of contributions to the theory of regional industrial development underlying second and third generations of regional policies. A distinction is made between macro-regional theories and those that have an industrial organization focus. The review includes a selected number of case studies drawn from Europe and Latin America.

Key words: Regi onal i ndustri al devel opnent, fl exi bl e speci al i zati on, i ndustri al di stri cts, net works, generati ons of regi onal pol icy, case studi es.
\end{abstract}

\section{Resumen}

Este artículo observa cambios sustanciales en las bases conceptuales de políticas de desarrollo industrial regional. Presenta una división entre varias generaciones de políticas. La 'primera generación' de políticas regionales se basó en la importancia de factores exógenos de crecimiento. La 'segunda generación' de políticas se focalizó en los factores endógenos locales. Desde la mitad de los años ochenta la base teórica que sustenta estas políticas recibió impulsos fuertes de nuevos puntos de vista derivados de la nueva literatura sobre 'especialización flexible' y distritos industriales. Se está formando una nueva y 'tercera generación' de políticas que va más allá del crecimiento endógeno y que busca superar la separación entre políticas endógenas y exógenas. Aquí se presenta una revisión de las contribuciones a la teoría del desarrollo industrial regional que sustentan las políticas de segunda y tercera generación y una clasificación entre teorías macrorregionales y aquellas basadas en un enfoque de organización industrial. Esta revisión incluye un número selectivo de estudios de casos de Europa y América Latina.

Palabras claves: Desarrol I o i ndustri al regi onal, especi al i zaci ón fl exi bl e, di stri tos i ndustri al es, redes, generaci ones de políticas regi onal es, estudi os de caso de Europa, Améri ca Lati na.

\footnotetext{
${ }^{1} \mathrm{El}$ autor es profesor de desarrollo local y regional, Instituto de Estudios Sociales, AA 29776, 2502 LT La Haya, Holanda (Correo electrónico: Helmsing@iss.nl).

Una primera versión de este trabajo fue presentada bajo el mismo título en el Cuarto Seminario Internacional de la Red Iberoamericana de Investigadores de Globalización y Territorio, abril 22-24, 1998, Santa Fe de Bogotá, Colombia. Una segunda versión de este trabajo apareció como "Industrialización y regiones: nuevas teorías y políticas", en el Cuaderno de Ciencias Sociales, No 110, FLACSO, sede Costa Rica. El autor agradece las contribuciones de Cristina Barajas y Camilo Villa en la edición de este trabajo.
}

Revista eure (Vol. XXV, No 75), pp. 5-39, Santiago de Chile, septiembre 1999 
A. H. J. (Bert) Helmsing

I. Re-PENSANDO EL DESARROLlO REGIONAL. TRES GENERACIONES DE PERSPECTIVAS DE POLÍTICA

$\mathrm{L}$ as perspectivas sobre políticas del desarrollo regional han cambiado considerablemente en los últimos treinta años. Para el propósito de este trabajo haremos la distinción entre tres generaciones de perspectivas políticas. ${ }^{2}$ La primera generación de políticas de desarrollo regional surge en los años $50 \mathrm{y}$ 60 bajo la perspectiva de la redistribución de crecimiento económico. Era entonces de conocimiento general y un hecho empíricamente comprobado que el crecimiento económico no se daba simultáneamente en todas partes del territorio sino que era desigual y selectivo. $\mathrm{Su}$ carácter acumulativo era aceptado por muchos y la cuestión central concernía a su permanencia estructural y al proceso de su reproducción. Existían diferencias apreciables en términos de interpretación, tales como si la desigualdad se incrementaría o decrecería con el tiempo. Las teorias de centro-periferia argüían que factores estructurales podrían reproducir e intensificar las desigualdades regionales.

Otras interpretaciones fueron más optimistas y predecían que las desigualdades podrían declinar con el tiempo. En su mayoría las políticas regionales fueron formuladas en la variante optimista y fueron derivadas de las teorías neoclásicas de la distribución óptima de recursos. Estas políticas entonces se orientaron a reducir los impedimentos a la movilidad de recursos y a transferir elementos monopólicos que mantuvieron

\footnotetext{
2 Maillat (1998) recientemente introdujo la noción de generaciones de políticas regionales. Este autor distinguió cuatro generaciones. Su clasificación y la que presentamos aquí coinciden en las primeras dos generaciones, pero existen diferencias en cuanto a las características de la tercera generación.
}

los precios fuera de sus niveles competitivos (Maillat, 1998). El gobierno nacional fue el actor central en las políticas de primera generación. Con sus políticas de regulación económica y a través de incentivos financieros buscaba influir sobre la localización de las empresas. La dotación con infraestructura fue un instrumento importante para estimular la demanda local y para reducir desventajas regionales. Las desigualdades regionales fueron el tema central en la teoría y la política de desarrollo regional. ¿Son las políticas regionales capaces de influir sobre patrones estructurales y reducir desigualdades regionales?

En los años 70 y al inicio de la década de los 80 surgió bastante escepticismo sobre la efectividad de los instrumentos convencionales de política de desarrollo regional y mientras duró el debate sobre su eficacia o la falta de ponerlas en la práctica ( $c f$. Boisier, et al., 1982) ocurrieron dos cambios importantes. El primero fue la búsqueda de alternativas de desarrollo regional. El otro se refiere a cambios fuertes en el entorno económico y político internacional. Ya en los últimos años de los setenta, varios analistas del desarrollo regional estaban buscando modelos alternativos al pensamiento dominante. Por ejemplo, Walter Stohr propuso la 'clausura espacial selectiva' (Stohr y Fraser Taylor, 1981) y John Friedmann propuso un desarrollo agropolitano (Friedmann y Douglass, 1978). Aunque existen diferencias considerables entre ellos, tienen en común la búsqueda de un desarrollo alternativo basado en actores, recursos y capacidades locales.

Los cambios en las políticas económicas nacionales, la apertura económica, los procesos de reestructuración económica y la internacionalización de la producción durante los años 80 han cambiado la geografía económica. Regio- 
nes centrales existentes fueron seriamente afectadas por la reestructuración industrial. Al mismo tiempo surgieron nuevas regiones de crecimiento, conocidas como distritos industriales, las cuales han competido exitosamente en el comercio internacional. Ejemplos de éstas son la llamada 'tercera Italia' en la parte central-norte de Italia, el estado de Baden-Wurtemberg en Alemania, la zona occidental de Flandes en Bélgica. Estas experiencias generaron la base para un desarrollo industrial regional alternativo y demostraron la potencialidad del desarrollo industrial endógeno regional.

La especialización flexible y los distritos industriales redefinieron el marco de referencia para las políticas regionales y dieron origen a la segunda generación de políticas regionales de industrialización. La noción central de estas políticas de desarrollo regional endógeno fue "aumentar las capacidades de desarrollo de una región - generar un reto a la competitividad y las tecnologías internacionales con base en la movilización de sus recursos específicos y sus propias capacidades de innovación" (Maillat, 1998:7). Una diferencia importante con las políticas de la primera generación es que el gobierno ya no está en el centro de la política. Más bien el desarrollo industrial endógeno enfatiza los roles de la cooperación entre firmas, de los gremios industriales, de los sindicatos de trabajadores y de gobierno para desarrollar en conjunto las habilidades, los recursos y las 'reglas del juego'. La política pública sigue siendo importante pero en forma diferente. A continuación revisaremos la literatura de especialización flexible y de distritos industriales y veremos las características de estas políticas.

En este momento, finales de los noventas estamos virando hacia una tercera generación de políticas regionales industriales. Estas políticas de tercera generación en parte responden a los conocimientos avanzados y a la evaluación del desarrollo endógeno y sus políticas recientes. Por otra parte, estas nuevas políticas surgen del reconocimiento de que la globalización hace que sistemas regionales de producción industrial compitan entre sí, y no solamente sus firmas. Esto significa que las políticas nuevas no pueden ser exclusivamente locales, sino que deberán tomar en cuenta la posición y el posicionamiento económico de los sistemas regionales de producción dentro de un contexto global. Adicionalmente, las políticas recientes indican que las nuevas políticas no pueden ser exclusivamente locales o regionales hasta el punto de excluir políticas y contextos sectoriales e (inter)nacionales. La coordinación horizontal entre un número de actores suele ser complementada por coordinación vertical entre niveles. Las políticas de tercera generación se basan en el reconocimiento de que la nueva orientación no necesariamente requiere más recursos, sino de aumentar 'la racionalidad sistémica' en el uso de los recursos y programas existentes. La tercera generación en cierta forma supera la oposición entre políticas del desarrollo exógeno y endógeno.

Este trabajo tiene como propósito revisar las teorías recientes sobre desarrollo regional industrial y analizar sus implicaciones políticas. En la segunda sección haremos una revisión de las varias líneas teóricas basadas en la especialización flexible. Distinguiremos entre teorias macrorregionales y las perspectivas meso sobre agrupamientos $\mathrm{y}$ distritos industriales. Esta sección se complementará con una revisión de estudios de caso sobre agrupamientos y distritos. En la tercera sección examinaremos las políticas de segunda y tercera generación, sus actores e instrumentos 
A. H. J. (Bert) Helmsing

principales. En la última sección se presentan algunas conclusiones.

\section{EsPeCIALIZACIÓN FLEXIBLE Y DESARROLLO REGIONAL INDUSTRIAL}

\section{A. Introducción}

Las nuevas perspectivas sobre industrialización regional han sido importantes para el desarrollo de las políticas regionales de segunda y tercera generación, $\mathrm{y}$ tienen en común las nociones de especialización flexible y de distritos industriales. A continuación revisaremos algunos de los elementos constitutivos de esas perspectivas, los cuales han sido combinados de diversas maneras por diferentes autores.

A mediados de los años 80 se anunció la especialización flexible como el nuevo modelo de desarrollo industrial, el cual podría retar a la producción fordista de gran escala (Piore y Sabel, 1984). La crisis económica que sufrían Europa y los EE.UU. en esa época fue vista como indicio de que la producción masiva y en gran escala habría llegado a sus límites como modelo dominante de industrialización. La especialización flexible fue presentada como una alternativa para una prosperidad futura. Los dos modelos fueron considerados como opuestos polares. El primer polo consistía en la producción masiva de gran escala con base en una tecnología de maquinaria dedicada, de propósitos únicos, y operados por obreros semicalificados. La especialización estaba impulsada por esta tecnología y fue el resultado de una creciente refinación de las tareas de los obreros (conducente a bajar la calificación necesaria). La reformulación ('retooling') de estas operaciones crecientemente más complejas se volvió cada vez más costosa en tiempo y recursos y los volúmenes de cada tiraje de producción debió aumentarse cada vez más. En contraste, el otro polo, el de la especialización flexible, se basó en la manufactura de productos con especificaciones de los clientes y con una maquinaria con tecnología de múltiples propósitos y métodos de producción flexible, operados por trabajadores calificados. Los tirajes de producción podían ser más pequeños ya que los tiempos y costos de reprogramación de la maquinaria eran bajos. Los productos podían ser más diferenciados. La innovación en el diseño de los productos se convirtió entonces en un reto alternativo para evitar la competencia por precios para productos homogéneos.

La producción fordista requiere de estabilidad y de mercados masivos y homogéneos. Los choques económicos de los años 70 y del inicio de los años 80 produjeron rupturas en estos mercados. La demanda decreció y la capacidad de los gobiernos para mantener la estabilidad macroeconómica llegó a sus límites políticos y fiscales. Según Piore y Sabel, ya había en ese momento algunos distritos industriales en donde la especialización flexible había tomado fuerza en firmas pequeñas constituyendo un reto para la producción masiva. Los más famosos se conocían como la 'Tercera Italia', situados en las partes noroccidentales y centrales de ese país, en donde grandes concentraciones de firmas pequeñas y medianas fueron exitosas en la manufactura a pesar de la creciente competencia internacional. Estos desarrollos contrastaban fuertemente con otras regiones en Europa, donde los mismos sectores industriales fueron concentrados en firmas grandes y/o donde la producción decreció y se trasladó hacia países de bajos salarios.

Este éxito de firmas pequeñas estuvo basado en una larga tradición de artesanos en la manufactura de productos 
'hechos a la medida'. La nueva tecnología de maquinaria computarizada permitió a estas firmas responder de forma más flexible a los cambios en la demanda de las especificaciones de estos productos (Piore y Sabel, 1982; Sengenberger y Pyke, 1991; Pedersen et al., 1994). En lugar de organizar todo un proceso productivo dentro de su propia planta, una firma puede optar por conseguir ciertas partes o componentes de otras firmas. La especialización es ventajosa para cada una de las firmas pequeñas y así surge una división progresiva de trabajo entre ellas. La subcontratación entre las firmas constituye la base de una especialización sectorial.

La especialización flexible en firmas pequeñas y medianas surgió de forma concentrada geográficamente. Las economías internas de escala, que habían sido la base de la producción a gran escala en una firma, fueron reemplazadas por economías externas que surgen de la división de trabajo entre muchas firmas. En esta concentración de firmas, conocidas como agrupamientos, también surgen economías de alcance, ya que aumenta la variedad de tipos de firmas, algo que facilitará nuevas combinaciones de recursos de producción.

El libro Second Industrial Divide de Piore y Sabel ha sido criticado en algunos aspectos. Williams et al. (1987) presentan una crítica elaborada y poderosa. Según estos autores la oposición polar entre producción masiva y especialización flexible es problemática. También en la producción masiva se logró bajar los tiempos para reprogramar la maquinaria, por ejemplo, en la adopción de diseños modulares de productos en donde se combina la flexibilidad con tirajes muy grandes de producción y se logra una diferenciación del producto al mismo tiempo. “...(E)quipos dedicados y una variedad limitada de productos no son características sin problema que puedan ser utilizadas para diferenciar firmas e industrias de producción masiva de los demás" (Williams, et al. 1987: 416). Sistemas fordistas de ensamblaje están en uso solamente en una pequeña parte de la industria manufacturera. Sólo constituyen una ventaja en el caso de la manufactura de productos con un gran número de componentes, pero son menos eficaces para productos menos complejos. Los costos directos de mano de obra solamente constituyen una fracción de los costos totales de producción.

La ruptura de los mercados también fue sujeto de crítica. En lugar de una ruptura puede haber ocurrido una saturación y la demanda de reemplazo podría haber llegado a estabilizarse. En estas condiciones las firmas buscan desarrollar nuevos productos para poder seguir creciendo. También los mercados pueden haberse fragmentado bajo el impacto de las crecientes exigencias de los consumidores y la competencia de las demás firmas, pero esto en sí mismo no es un argumento que socave la producción de gran escala. Por último, los sistemas de producción flexible tienen altos costos de desarrollo e iniciación (ibid::430). Estos costos fijos deben ser financiados al comienzo y esto constituirá una barrera grande para firmas pequeñas, no sólo por el volumen restringido de su producción, que permite su recuperación, sino también por las dificultades de prefinanciar estos gastos.

No obstante estos puntos válidos de Williams, es importante señalar que hay una tendencia empírica que permite afirmar que el tamaño promedio de las firmas, medido en términos de empleo, ha bajado en muchos países. También la proporción de las firmas pequeñas ha aumentado. Cifras citadas por Sengenberger y Pyke (1991) confirman estas tendencias. Hay que agregar también que 
A. H. J. (Bert) Helmsing

grandes firmas puedan contribuir al crecimiento del número de firmas pequeñas, tanto a través de la descentralización como del desinvolucramiento y de la desintegración vertical (ibid.). La descentralización consiste en una reorganización de la firma grande en un número de pequeñas unidades, todas bajo la propiedad y el control central. El desinvolucramiento se relaciona con las prácticas asociadas con las licencias y franquicias a través de las cuales las firmas grandes pueden mantener vínculos con firmas pequeñas sin tenerlas en propiedad. La desintegración vertical se refiere a la externalización de la producción en unidades separadas de propiedad. La recesión de finales de los años 70 y 80 causó grandes pérdidas de empleo en firmas grandes, lo que también estimuló el crecimiento de la pequeña empresa.

En resumen, podría argüirse que hay otras formas de desarrollar producción flexible, y que no significan la desaparición de economías internas de escala. Aun si firmas grandes se desintegran verticalmente, esto no significaría la desaparición del 'control en gran escala'. Diciéndolo en forma diferente, aun si la especialización flexible constituyera el fin del 'fordismo' como forma de organizar producción en gran escala, esto no significaría la desaparición de las firmas grandes.

Asheim hizo un importante aporte al decir que el desarrollo de la tecnología de especialización flexible ha hecho posible que los métodos de producción flexible también hayan llegado a estar disponibles para las firmas pequeñas. "Un aspecto nuevo de la historia del desarrollo industrial capitalista es el de las oportunidades abiertas para firmas pequeñas para emprender producción diversificada y de calidad donde se consigue un grado alto de flexibilidad y eficiencia en la elaboración de productos hechos a medida y de calidad competitiva a través de una nueva capacidad de la firma pequeña para cambiar rápidamente de un producto o configuración de proceso hacia otro, gracias a la disponibilidad en el mercado del equipamiento de producción computarizado y programable y relativamente barato" (Asheim, 1992:50). La especialización flexible ahora adquiere un significado restringido y se refiere a "esta nueva forma de organización de la producción, con base en técnicas flexibles de producción de múltiples propósitos y de trabajadores calificados, que ha resultado en una nueva situación de mercado competitivo para empresas pequeñas e independientes" (ibid., p. 50, énfasis mío).

Se podrían distinguir dos líneas diferentes en los desarrollos teóricos posteriores. Una se refiere a teorías de nivel macro sobre industrialización y desarrollo regional, otra concierne a teorías de nivel meso sobre organización industrial y distritos industriales. A continuación revisaremos primero las teorías de nivel macro y luego detallaremos las teorias de la segunda línea.

\section{B. Teorias macrorregionales de especialización $y$ acumulación flexible}

Scott, Storper y Walker han contribuido a esta línea de indagación. Scott siguió el argumento inicial de Piore y Sabel (1984) de un contraste polar entre la producción fordista y flexible, pero lo desarrolló como dos regimenes contrastantes de regulación, basándose en la escuela francesa de regulación. Según el autor, la acumulación flexible está basada en tres conjuntos de sectores industriales: primero las industrias intensivas en desarrollo de diseño y en contenido artesanal produciendo principalmente para consumo final; segundo, los sectores industriales de alta intensi- 
dad tecnológica cada uno con su red asociada de proveedores de insumos y subcontratantes y, tercero, los sectores que representan funciones de servicio, especialmente los servicios empresariales (Scott, 1988). Su tesis central era que la producción flexible tiene "una tendencia de desintegrar en divisiones sociales de trabajo extendidas, y de esta manera, genera muchos subsectores especializados"... "Este proceso es una reflexión de la tendencia de que las economías internas se pierden frente a una progresiva externalización de la estructura de producción bajo condiciones de creciente flexibilidad y resulta asimismo... en una convergencia locacional y reaglomeración" (Scott, 1988:175). La creciente competencia e incertidumbre sobre la demanda expone a las firmas a altos niveles de riesgo, los cuales no se pueden compensar por economías internas de escala y alcance de mantener un sistema productivo entero, y como resultado, las firmas empiezan a desintegrarse verticalmente. Esto último induce al proceso, descrito arriba, por lo cual surgen aglomeraciones de productores especializados. En la medida en que las economías externas crecen, las firmas pueden adquirir insumos diversos a precios más bajos. Mientras más aumentan las compras de insumos, también crecen los costos de transacción. Estos pueden mantenerse bajo control cuando se concentren los productores espacialmente. Así se dará una concentración adicional de la producción. Esta reaglomeración de la producción conlleva el surgimiento de nuevos espacios industriales y de economías regionales.

En términos del mercado laboral, este proceso resulta en una diferenciación entre trabajadores altamente calificados quienes juegan un papel clave en los procesos centrales de producción y los trabajadores menos calificados y sin calificación. Los aumentos en la produc- tividad en los procesos centrales entonces no se distribuyen a todos los trabajadores y esto constituye la base de la nueva acumulación flexible. Nuevas formas de trabajo y de contratación resultan en mercados laborales más flexibles.

La crítica de Lovering a la teoría de Scott en parte repite los puntos de Williams et al. $\mathrm{El}$ autor cuestiona la supuesta desaparición de la producción fordista, siendo exclusivamente causada por la desaparición de economías de escala, etc. También critica a la proposición de Scott de que la externalización bajo condiciones de especialización flexible genera nuevos regímenes de acumulación sin dar cuenta de procesos históricos y sociales más amplios e ignorando la dimensión del estado-nación (Lovering, 1990).

En 1992 Scott y Storper publicaron una reformulación en la cual tomaron en cuenta algunas de estas críticas. Un sistema territorial de producción consta de cuatro niveles. En el nivel más bajo funcionan las unidades productivas $o$ plantas. Estas tienen vínculos entre ellas mismas. Las unidades vinculadas por las firmas conjuntamente constituyen aglomeraciones.

Una región se define como un sistema económico coordinado. Para poder generar retornos crecientes de escala, las firmas buscan economías de escala y de alcance. Estas economías pueden generarse dentro de las firmas o externamente en las aglomeraciones. Los autores definen una tipología macro de sistemas productivos en términos de la importancia relativa de estas economías (alto o bajo) y de la manera como se generan (internamente o externamente). Se sostiene que a raíz de la creciente competencia y la mayor incertidumbre, las firmas no quieren generar economías internas de escala y alcance sino que pre- 
A. H. J. (Bert) Helmsing

fieren generar éstas externamente. Los métodos de producción flexible lo hacen posible.

La aglomeración no sólo contribuye a bajar los costos de producción, sino también a una reducción en los costos de transacción, ya que "proximidad se traduce en menores costos y mayores oportunidades de combinar necesidades y capacidades" (ibid., 1992:17). Sin embargo, los autores agregan que la aglomeración en sí misma no es una condición suficiente para reducir los costos de transacción. Los autores invocan elementos de la 'nueva economía institucional' por agregar que la información necesaria no es perfectamente disponible, existen asimetrías en la información y éstas pueden resultar en costos mayores de transacción. Tanto instituciones reguladoras como ciertas prácticas sociales son importantes para mantener los costos de transacción a niveles más bajos, a través de controlar el oportunismo. Adicionalmente, la innovación tecnológica requiere apoyo institucional, ya que las firmas no son capaces de absorber todos los costos individualmente. La innovación es crucial para mantener ventajas competitivas y éstas son creadas crecientemente por las firmas mismas y menos por la dotación de recursos del país o de la región. Resumiendo, las aglomeraciones representan un inventario de economías externas, instituciones y capital económico y social, las cuales conjuntamente constituyen la capacidad productiva de un territorio. "La idea de que una reproducción exitosa del sistema económico no puede darse sin la presencia de agencias institucionalizadas y la acción colectiva no sólo se sostiene a nivel de la economía nacional sino también a nivel de la economía regional, donde se dan formas peculiares e imperativas de orden institucional a raíz de la especialización, aglomeración y el carácter locacional específico de la produc- ción" (1992:16/7). Existe una amplia variedad de instituciones y regímenes de mercado, que van desde los muy competitivos hasta otros con altos niveles de concertación formal o informal.

La creciente interacción e intercambio global hace que sistemas regionales de producción compitan entre sí. Esto genera presiones para que los sistemas regionales de producción se adapten. "Regiones en las que la concertación se ha desarrollado débilmente y en donde predomina la competencia con bajos niveles de regulación, encuentran mayores problemas y dificultades que pueden comprometer la viabilidad a largo plazo. Estas regiones son cada vez más vulnerables porque en un mundo de mercados competitivos se encuentran con competidores basados en regiones que sí ofrecen servicios efectivos de concertación"... "La viabilidad de los sistemas contemporáneos de producción flexible depende hasta cierto punto de una construcción efectiva de instituciones a nivel regional" (1992:22). En otras palabras, la viabilidad o fuerza de sistemas regionales de producción depende no solamente de sus firmas sino de las instituciones de regulación, concertación y apoyo.

\section{Especialización flexible $y$ desarrollo del Tercer Mundo}

Storper ha examinado la especialización flexible en relación con la industrialización en el Tercer Mundo. Sostiene que la teoría de la industrialización con base en la sustitución de importaciones buscaba trasladar al por mayor la producción fordista pero sin las instituciones sociales y regulatorias necesarias, resultando en una forma dependiente de industrialización (Storper, 1990). Gran parte de la industrialización estaba basada en el ciclo de producto de innovación tecnológica donde se trasladaron 
únicamente procesos productivos ya maduros en términos tecnológicos, y en forma entera a países de bajo costo. En estos países la estrategia fracasó, entre otras razones, porque el crecimiento de la demanda era insuficiente para inducir etapas más avanzadas en la industrialización con base en la sustitución de importaciones. Los mercados nacionales pequeños y protegidos sacaron la presión sobre las firmas para innovar sus productos. La innovación tomó lugar a través de la importación de componentes y diseños. La competencia muchas veces tenía características oligopólicas. Los grandes excedentes de mano de obra redujeron mucho el poder de los trabajadores y de los incrementos de salarios y esto, a su vez, redujo el crecimiento de la demanda interna.

En los años ochenta apareció la producción flexible. Aqui Storper continúa fundándose en el modelo de 'la segunda división' pero refinó la noción de flexibilidad. Los sistemas de producción flexible consisten en "formas de producción caracterizadas por una capacidad tanto de cambiar de un proceso y/o configuración de productos hacia otra ('flexibilidad dinámica') como de ajustar las cantidades de producción hacia arriba o hacia abajo a corto plazo ('flexibilidad estática')" (1990:431). Entonces se genera la flexibilidad de tres maneras: primero, a través de la aplicación de tecnología de producción flexible dentro de la firma; segundo, a través de la desintegración horizontal y vertical y una creciente división de trabajo entre las firmas y, por último, a través de una flexibilización de la fuerza de trabajo, inclusive la creación de sistemas de putting out (ibid:: 431).

Los mercados mundiales cambiaron como resultado de este mismo proceso. Resultó una mayor interpenetración de mercados y se han vuelto contestables, creando mayores riesgos por parte de los productores existentes: producción flexible no sólo es causa de estos dos fenómenos, sino también un efecto, en la medida que induce a una mayor diferenciación de mercados y nichos de productos más restringidos. La diferenciación de los mercados inducirá a los productores a expandirse a nuevos mercados y a buscar la exportación con el fin de recuperar la inversión asociada (ibid:432). La exportación es entonces un corolario de la especialización flexible.

Un elemento central del argumento de Storper es que los sistemas de producción flexible son de carácter regional o territorial. Mientras la industrialización fordista y con base en plantas subsidiarias se había vuelto 'a pie' (footloose), los sistemas de producción flexible requieren de la aglomeración. Además, se precisa de instituciones locales, infraestructura física y económica para poder generar flexibilidad dinámica.

Según Storper, los sistemas regionales de producción flexible constituyen una nueva oportunidad para el desarrollo industrial en los países del Tercer Mundo; presenta varios argumentos en ese sentido. Como se discutió arriba, existen límites a la descentralización de la producción desde los países avanzados hacia los países pobres con base en el 'modo fordista'. Además la especialización flexible presenta oportunidades para que nuevas firmas puedan competir en mercados existentes. Esto requiere de políticas industriales regionales diferentes. El énfasis en polos de crecimiento y en la empresa pequeña son ambos inadecuados, ya que según Storper: "El énfasis aquí no está en reforzar la pequeña empresa en sí misma ..., sino en firmas de diferentes tamaños y con funciones diferentes en relación con un sistema de firmas que conjuntamente conforman un proceso productivo" (ibid:: 435). La noción de polo de crecimiento 
A. H. J. (Bert) Helmsing

debe ser revisada ya que se basa en la capacidad de grandes inversiones de firmas externas. Los nuevos Sistemas Regionales de Producción (SRP), sin embargo, están basados en el desarrollo 'desde abajo' de una división social de trabajo. El desarrollo de un SRP es extremadamente selectivo, ya que requiere satisfacer un número de precondiciones. $\mathrm{El}$ aspecto clave es que las politicas sectoriales y espaciales deben ser desarrolladas en conjunto y alrededor de regiones o localidades específicas (énfasis mío) y no a través de políticas generales.

\section{Perspectivas del nivel meso sobre especialización flexible: empresas pequeñas $y$ distritos industriales}

El segundo grupo de teorías sobre la especialización flexible se concentra menos en el nivel macrorregional y en los aspectos espaciales y más en la empresa pequeña y sus interacciones dentro de una aglomeración: el distrito industrial. Mientras algunos autores se dedican exclusivamente a la empresa pequeña, otros conceptualizan un marco de referencia más amplio. Todos tienen en común que el análisis se concentra en firmas y las relaciones entre firmas, más que en sistemas regionales de producción. Predomina una perspectiva de organización industrial.

Mientras que en los años pasados se vio la pequeña empresa en desventaja frente a las firmas grandes, la especialización flexible ha creado nuevas oportunidades para la empresa pequeña. El agrupamiento de empresas pequeñas en distritos industriales les da ventajas adicionales que les permiten competir (Asheim, 1992:50). Muchos autores reconocen que la especialización flexible no se restringe a las empresas pequeñas. Sin embargo, en muchos países en desarrollo las empresas pequeñas dominan la estructura industrial y existen pocas firmas grandes. Es entonces relevante examinar la aplicabilidad de la especialización flexible y de los distritos industriales para la industrialización con base en empresas pequeñas.

La concentración geográfica de empresas industriales (pequeñas) no es un fenómeno nuevo. La teoría de localización industrial indica varios factores (Smith, 1976 y Gilbert, 1979). La demanda puede ser concentrada geográficamente, o ciertos insumos esenciales se consiguen en un lugar, y/o hay factores de acceso a fuerza de trabajo especializado. Tal tipo de concentración geográfica sería nada más que un conjunto atomizado de empresas. Un distrito industrial podría ser producto de estos factores locacionales pero debería generar ventajas y procesos adicionales. Diferentes autores enfatizan distintos aspectos. A continuación revisaremos los principales elementos y este análisis se complementará con una revisión de estudios de casos de agrupamientos y distritos industriales en Europa y América Latina.

\section{Distritos industriales}

Existen muchas definiciones de distritos industriales, de tal modo que se ha convertido en un término genérico que denomina una gran variedad de situaciones (Van Dijk, 1994). Muchos autores se basan en Marshall (1891) quien fue el primero en describir la noción de distrito industrial como una concentración geográfica de pequeños productores, especializados en la elaboración de ciertos productos particulares. La atención se centra en las economías externas generadas por la división de trabajo a nivel del distrito, algo que podría compensar la falta de economías internas que las pequeñas empresas por sí mismas puedan generar. Estaría fuera de la capacidad y de los recursos de las fir- 
mas pequeñas organizar un proceso productivo entero dentro de su planta. La subcontratación entre firmas constituiría la base de la especialización sectorial. Así, el distrito representa una especialización progresiva de todas las firmas trabajando en el mismo sector y en la misma área (Brusco, 1989:259).

Sengenberger y Pyke (1991) definen los distritos industriales como "redes de firmas principalmente pequeñas, las cuales a través de la especialización y la subcontratación se dividen la labor requerida para la manufactura de bienes particulares; la especialización induce a la eficiencia, tanto a nivel individual como a nivel del distrito; la especialización en combinación con la subcontratación promueve la capacidad colectiva. Resultan así economías de escala y de alcance" (1991:1).

Las ventajas del agrupamiento geográfico de firmas que surgen de la división sectorial de trabajo se llaman economías de localización. La concentración geográfica genera ventajas adicionales, es decir, las economías de aglomeración. Hay oportunidad para reducir los costos de transacción. Existe un entorno informacional más rico. Además, la mayor variedad de demandas, productos y productores genera mayores oportunidades para la innovación. Sólo se requiere dinamismo empresarial para aprovechar aquellas oportunidades.

Otro aspecto, elaborado inicialmente por Marshall y adoptado por muchos autores que trabajan sobre distritos industriales, se refiere a la llamada 'atmósfera industrial'. Las firmas que conforman un distrito frecuentemente desarrollan nuevas prácticas de negocios basadas en la confianza entre ellas. Se generan ciertas tradiciones de comportamiento o valores. En las interpretaciones modernas, la 'atmósfera industrial' constituye la base para generar nuevas formas de cooperación entre firmas y para la acción colectiva por parte de ellas, conduciendo a la formación de distintos tipos de asociaciones empresariales. El éxito de un distrito industrial se encuentra en estos aspectos sociales e instituciones de fondo (Asheim, 1992).

Un distrito industrial genera ventajas de costos, crea oportunidades para un aprendizaje más rápido y para la innovación y el mejoramiento tecnológico. Visser (1996) tomó estas tres fuentes localizadas de ventajas competitivas y examinó su aplicabilidad para agrupamientos de empresas pequeñas. Visser desarrolló su argumento desde la perspectiva de la teoría de la firma. Las firmas ejercen cuatro funciones: transformación de insumos en productos, compra y venta, innovación en productos y procesos, y gerencia y manejo de riesgo. La competitividad puede basarse en tecnología, en precios de insumos, en la capacidad reactiva e innovadora y en ventajas en las relaciones con los demás agentes económicos. El tamaño juega el papel de reforzar la competitividad: en términos de escala y composición de la producción, las experiencias acumuladas, el grado de especialización vertical y el conocimiento. Este autor se preguntó si el agrupamiento y las interacciones más intensas entrefirmas podrian iniciarse a partir de las desventajas del pequeño tamaño de las firmas. Para poder analizar este aspecto se debe aclarar la noción del 'entorno empresarial'. Este entorno empresarial, según Visser, tiene tres dimensiones. La primera se refiere a las interrelaciones funcionales entre las firmas, las cuales implican riesgos y costos de transacción. La segunda se refiere a la dimensión institucional, que tiene un desarrollo histórico importante y que tiene en cuenta las interacciones entre empresarios, sus organizaciones y las instituciones regulatorias. 
A. H. J. (Bert) Helmsing

En esta dimensión surgen las prácticas de negocio, las cuales a su vez influyen sobre los costos de transacción y sobre los patrones de subcontratación. La tercera dimensión es la territorial, la cual tiene en cuenta la configuración específica de la dimensión funcional e institucional. Estas pueden variar según las distintas localidades.

Visser define un agrupamiento de firmas, en una forma bastante amplia, como una "concentración geográfica de actividad subsectorial y con un cierto desarrollo de la experiencia industrial; las fuerzas motrices pueden variar desde similitudes entre firmas en su estrategia empresarial, hasta un cierto grado y tipo de interdependencia de firmas" (Visser, 1996:227). Los elementos característicos son la alta densidad de actividades, la proximidad de los actores y una historia local distinta. La proximidad generará economías de costos, la densidad contribuirá a una difusión (más rápida) de información y conocimientos, mientras que la historia local influirá sobre los efectos de aprendizaje y los efectos dinámicos del cambio (ibid.).

\section{Eficiencia y acción colectiva}

Otro grupo de autores pone mayor énfasis en la generación de eficiencia colectiva con base en la acción colectiva por parte de las empresas pequeñas como manera de superar sus desventajas de tamaño y ponen menos atención a los fenómenos de agrupamiento espacial y de economías de aglomeración (véase Schmitz, 1989; Sengenberger y Pyke, 1991; Spath, 1991; Pedersen et al. 1994). El problema principal de las empresas pequeñas no es que sean pequeñas sino que están aisladas: "como empresas individuales, actuando individualmente, están en una posición débil para competir. Les faltan recursos, economías de escala y de alcance de las cuales dispo- nen las firmas grandes y les falta una voz política necesaria para influir sobre su propio entorno económico y político" (Sengenberger y Pyke, 1991:8). "El problema principal de las empresas pequeñas es su aislamiento y falta de poder, sobre todo en un ambiente que favorece a las grandes empresas privadas y públicas" (Spath, 1991:4). Cuando se unen sus esfuerzos y se juntan conocimientos y recursos las empresas pequeñas pueden actuar mejor. La formación de redes entre las empresas pequeñas es crucial.

Sengenberger y Pyke distinguen entre un camino 'hacia arriba' y 'hacia abajo' en la reestructuración industrial. El camino 'hacia abajo' de la reestructuración es aumentar la capacidad competitiva en los mercados a través de bajar los costos de trabajo y de regular el entorno laboral. Es una forma de competitividad destructiva pero que puede ser muy exitosa. El camino 'hacia arriba' es el alternativo que se basa en aumentar la eficiencia e innovación a través de una mejor organización, movilización de recursos y protección de los derechos y los salarios de los trabajadores. Estándares laborales altos no solamente estimulan a la firmas a innovar, sino que también hacen posible la innovación (Sengenberger y Pyke, 1991).

\section{Redes y acción de redes}

Algunas contribuciones de los distritos industriales a la especialización flexible enfatizan en el papel central de la aglomeración y del agrupamiento espacial, mientras que otras se concentran en las redes y su formación que no necesariamente se expresan en forma geográfica (como lo definió Porter). Las redes tienen muchas veces un significado doble. Por un lado, las redes se refieren a las relaciones entre firmas, especialmente en cuanto a la subcontratación. El elemen- 
Teorias de desarrollo industrial regional y politicas de segunda y tercera generación

to central es la relación funcional entre firmas. Por otra parte, las redes pueden ser vistas como una tercera forma híbrida de coordinación económica, al lado de la coordinación basada en mercados y la coordinación basada en jerarquías. Aquí el elemento central son las transacciones entre firmas. La hibridación se refiere al hecho de que dentro de contextos de mercados las firmas pueden preferir desarrollar relaciones (semi-)permanentes, con base en contratos formales o en mecanismos informales. A esta forma de relación entre firmas se le llama redes entre firmas, y se refiere a relaciones de larga duración (Thompson, 1991). Es importante en este contexto distinguir entre redes horizontales y redes verticales. Gran parte de la literatura sobre distritos industriales y especialización flexible considera a las redes como un conjunto de relaciones horizontales y que las firmas son pequeñas e independientes. Esto no necesariamente es así. Las relaciones entre firmas pueden ser muy desiguales y muchas veces son relaciones formales de dependencia (por ejemplo cuando una firma ensambladora final adquiere un control de acciones en firmas que producen componentes). Alternativamente, pueden formarse redes verticales cuando una firma grande descentraliza sus operaciones a empresas separadas. Por último, las interdependencias en una red pueden ser generadas y mantenidas por medidas extraeconómicas.

Las tres formas de coordinación económica no son mutuamente exclusivas, ya que redes horizontales tienen mucho en común con el intercambio de mercado y las redes verticales con el intercambio coordinado por jerarquías (Powell, 1991; Knorringa, 1996). Cada vez es más reconocido el hecho de que se pueden bajar los costos de transacción gracias a la confianza generada por las relaciones sociales y que las relaciones de in- tercambio forman parte integral de la organización social.

La subcontratación ha sido el otro enfoque de redes. En este contexto vale la pena señalar que la especialización flexible ha contribuido a alterar la visión sobre subcontratación. Sobre todo los teóricos del desarrollo de empresas pequeñas mantuvieron una posición mixta sobre la subcontratación. Algunos enfatizaron en los aspectos positivos de subcontratación, especialmente porque puede generar nuevas oportunidades en los mercados intermedios. Las firmas contratantes pueden ejercer una influencia positiva sobre la eficiencia de las empresas pequeñas subcontratadas y sobre su capacidad de innovar (véase Liedholm y Mead, 1989). Otros enfatizaron en aspectos negativos de la subcontratación, como en la relación de dependencia entre las firmas (grandes) contratantes y las empresas pequeñas subcontratadas (subcontratación dependiente). Gran parte de la literatura sobre los distritos industriales asume, lo que Visser llamó, 'la subcontratación interdependiente' (Visser, 1996).

En este contexto es también útil conocer la distinción entre subcontratación industrial y comercial (Knorringa y Weijland, 1993). En la subcontratación comercial, el contratante es un intermediario comercial/financiero que no participa en los procesos productivos pero quien organiza una red de productores. Muchas veces el contratante les provee insumos centrales o prefinancia (una parte de) la producción. El contratante controla normalmente la información de mercadeo y de mercado a la cual los productores subcontratados no tienen acceso. En la subcontratación industrial, el contratante mismo es un productor industrial y utiliza las unidades productivas subcontratadas para ciertas tareas en el proceso productivo (ibid., 1993). 
A. H. J. (Bert) Helmsing

Una buena parte de la literatura de distritos industriales y especialización flexible está enfocada hacia la subcontratación industrial e interdependiente.

La dinámica de las redes es un asunto importante y debatido. ¿Las redes se mantienen en forma horizontal o se da una diferenciación en la medida en que las empresas más exitosas desde dentro empiezan a dirigir al agrupamiento de firmas, adquiriendo posiciones centrales de coordinación y control, formando parte del agrupamiento o actuando desde afuera? ¿Deben las redes ser horizontales para ser ventajosas para las empresas pequeñas? Existen varias posiciones al respecto. Una posición es que las relaciones entre empresas pequeñas y firmas grandes produce relaciones asimétricas y son desventajosas para las empresas pequeñas. Pueden resultar así fenómenos de explotación. Otros se aproximan al asunto desde un ángulo empírico. En su estudio de dos encuestas de firmas en el estado de Nueva York, Young y otros encontraron que muchas de las proposiciones centrales de la especialización flexible se dan en esa realidad (como por ejemplo la tecnología, los productos hechos según las especificaciones solicitadas por el cliente, encaje social de las transacciones), pero las empresas pequeñas no interactúan exclusivamente entre ellas mismas. Se forman redes regionales alrededor de firmas centrales oligopólicas. Muchas empresas pequeñas son proveedoras regulares de estas firmas. Sin embargo, las empresas pequeñas también venden su producto fuera del agrupamiento y las redes no las tienen cautivas o dependientes (Young y otros, 1994:37). Recientemente, Echeverri-Caroll y otros llegaron a una conclusión similar investigando a firmas en sectores de alta tecnología en una región metropolitana norteamericana. Las empresas pequeñas no comprometen su independencia cuando en- tran en redes asimétricas. Se benefician de la información y conocimientos de las firmas grandes. Esto se explica principalmente por el hecho de que estos vínculos no exceden a más de $25 \%$ de las ventas (compras). Al mismo tiempo la relación las hace más competitivas. (Echeverri-Carroll et al., 1998). Otros estudios de caso demuestran lo contrario. Por ejemplo, Cho (1994) en su estudio en tres agrupamientos regionales en Corea del Sur encontró que surgieron redes complejas pero flexibles de cooperación entre firmas y tanto firmas grandes como empresas pequeñas conformaban estas redes. Particularmente en los sectores intensivos de trabajo, grandes firmas han descentralizado su producción hacia empresas pequeñas y esto lo han hecho como una estrategia de descentralización de los problemas de gerencia laboral y con el fin de concentrarse ellas mismas en el diseño, el mercadeo y la coordinación de proveedores en pequeña escala en redes de subcontratación dependiente (Cho en Pedersen et al., 1994).

Para poder diferenciar en tipos, Markusen (1996) hizo una clasificación de distritos industriales: el primero es el distrito de 'tipo italiano' en el cual firmas pequeñas predominan; el segundo se llama el distrito rueda (hub and spo$k e$ ) en donde firmas grandes del distrito organizan la subcontratación a través de redes asimétricas; el tercero es el distrito satélite. En este caso las firmas en el distrito están vinculadas a firmas grandes no localizadas en el distrito. Por lo tanto la interacción entre las firmas dentro del distrito es baja. El cuarto tipo es el distrito basado en política pública, como por ejemplo complejos de industria militar o universidades estatales. 
Teorias de desarrollo industrial regional y politicas de segunda y tercera generación

\section{Estudios de caso de agrupamientos $y$ de distritos industriales}

La comprobación empírica de las proposiciones principales de la especialización flexible y de los distritos industriales se complica por el hecho de que se carece de un número adecuado de estudios empíricos muy detallados. A continuación revisaremos algunos casos de distritos industriales en Europa y en América Latina. Schmitz y Musyck revisan las características principales de distritos industriales en Europa. Estos distritos se dedican a la producción de textiles, zapatos, muebles, loza e ingeniería mecánica en la llamada 'tercera Italia', a ropa de vestir y muebles en Jutland, Dinamarca, a productos de metal e ingeniería mecánica y vehículos en BadenWurtemberg, Alemania, y a fabricar alfombras, verduras congeladas y componentes de computadores en el suroccidente de Flandes, Bélgica (Schmitz y Musyck, 1994:890). En otras palabras se refieren también a sectores industriales similares a los que se encuentran en muchos de los países en vía de desarrollo. Generalmente, los distritos han sido exitosos en exportar internacionalmente gracias a la innovación más que basándose en la reducción de salarios y en la flexibilidad de trabajo. Lo anterior indica que siguieron el "camino hacia arriba' de la industrialización. Los autores enfatizan en la importancia de las instituciones de apoyo en este contexto. El caso de Baden-Wurtemberg ha sido más estudiado. Según Schmitz (1992), las firmas pequeñas y medianas no dominan el distrito, sino las firmas grandes. Existen diferencias de opinión entre diferentes autores sobre el grado de cooperación entre las firmas. Schmitz enfatiza que el gobierno regional ha jugado un papel importante, como lo han hecho las asociaciones gremiales y demás instituciones intermedias. Cooke y Morgan
(1994) son más críticos en cuanto a la capacidad innovadora de las firmas medianas y tienen más dudas sobre las perspectivas futuras del distrito frente a la competencia global.

Rabelloti (1995) comparó dos distritos de empresas pequeñas y medianas dedicadas a la producción de zapatos en Italia (Brenta y Marche) con dos distritos en México (Guadalajara y León). En ambos países encontró fuertes vínculos 'hacia atrás' entre las firmas y sus proveedores. En el caso de México estos vínculos en las firmas se dieron en los mercados, mientras que en Italia tuvieron un alto grado de relaciones de cooperación, más de acuerdo con el planteamiento teórico. Los vínculos 'hacia adelante' fueron débiles, tanto en los distritos italianos como en los mexicanos. También había un sesgo hacia la función de producción, mientras que las funciones comerciales y de mercadeo fueron débilmente desarrolladas. Las instituciones de apoyo fueron examinadas parcialmente y parecía que jugaban un papel no muy fuerte en los cuatro casos. En México las relaciones entre las firmas y las instituciones de apoyo fueron más bien de carácter informal, mientras que en los distritos italianos estas relaciones se desarrollaron en redes solidarias. Rabelloti estudió a los distritos en una época de cambios muy fuertes en los mercados internacionales. "El modelo estático del distrito industrial no toma en cuenta la posibilidad de que un cambio externo fuerte, como son los cambios en la posición competitiva de los casos, pueda constituir una ruptura en la trayectoria evolutiva de los distritos y que podría resultar en una forma organizacional muy distinta de la original y posiblemente bastante lejos de la tradición y el arquetipo del modelo" (Rabelloti, 1995:39). 
Wilson (1994) estudió la industria de ropa de vestir en México y encontró que a raíz de la creciente competencia internacional, las firmas establecidas adoptaron métodos de producción flexible, principalmente la subcontratación hacia microempresas y empresas basadas en los hogares. Es decir, como respuesta a la competencia intensiva, las firmas optaron por una vía 'subterránea' para evitar la legislación laboral, la regulación empresarial y los impuestos. Según Wilson, son "los trabajadores quienes fueron flexibilizados" (Wilson, 1994:153). En lugar de un agrupamiento, las firmas salieron de los centros industriales establecidos y se fueron a las áreas rurales, en donde los salarios eran mucho más bajos y donde es más fácil esconder la ilegalidad. Se aumentó la subcontratación pero en una forma dependiente. Así la flexibilización produce una informalización de la producción (véase también Rakowski, 1994).

Schmitz (1995) examinó el caso de un distrito de zapatos en el Valle de Sinos en el Estado de Rio Grande do Sul en Brasil. El agrupamiento representa el $30 \%$ de la producción nacional y el $80 \%$ de las exportaciones brasileñas de calzado. Consiste en unas 480 firmas que producen zapatos y unas 1.800 empresas con actividades aledañas y complementarias que producen maquinaria y generan servicios especializados para la producción de zapatos. En todos los aspectos corresponde a una concentración sectorial y geográfica grande con todas las características de una división de trabajo profunda. Esta división profunda se desarrolló gradualmente, pero la mayoría de las firmas continuó siendo ensambladoras finales de zapatos. Ninguna se había convertido en una firma intermedia dedicándose únicamente a la producción de insumos intermedios, componentes y piezas. Además se desarrollaron dentro del agrupamiento algu- nas firmas grandes. A lo mejor el agrupamiento fue un distrito industrial en el pasado reciente. Schmitz encontró un número de ejemplos de acción colectiva de las firmas como el establecimiento de instituciones de apoyo, tales como ferias y exposiciones, centros de aprendizaje, de investigación y dedicados al intercambio y difusión de información, etc. Se establecieron algunas asociaciones profesionales y de productores. La especialización flexible surgió al lado de la producción fordista en firmas grandes. La creciente competencia internacional en los años recientes resultó en volúmenes de compras más pequeños y tiempos de entrega más cortos y esto forzó a algunas de las firmas grandes a descentralizar parte de su producción y así las empresas pequeñas engancharon con las nuevas tendencias.

Meyer-Stamer estudió agrupamientos textileros, de ingeniería metálica y de cerámica en el Estado de Santa Catarina, Brasil (Meyer Stamer, 1998). Enfatizó (en contraste con Schmitz) que las condiciones económicas históricas de Brasil no fueron muy apropiadas para el desarrollo de distritos industriales sino para la integración vertical dentro de las firmas grandes. La ineficiencia de integración en escalas suboptimales fue compensada por la mayor insulación del entorno macroeconómico. Mostró que las condiciones de la nueva competencia en los años noventa solamente condujeron a que la industria de cerámica se desarrollara hacia un distrito industrial, mientras que las firmas metálicas y las textileras solamente llegaron a adoptar algunos elementos y en forma parcial. Visser (1996) estudió en mayor detalle el distrito de La Victoria en Lima, Perú, en donde encontró un agrupamiento grande de casi 2.000 empresas pequeñas y 50 firmas medianas dedicadas a la manufactura de prendas de vestir y unas 150 firmas de venta de equipos 
y componentes. Además el distrito contaba con más de 4.000 comerciantes de telas y accesorios. En el distrito de La Victoria se encontraban dos grandes mercados mayoristas que atraían muchos clientes tanto de Lima mismo como de otras partes del Perú. Además el distrito contó con buenas conexiones de transporte con el resto del país. El autor estudió un agrupamiento de empresas de ropa de vestir de Gamarra y lo comparó con grupos de control generados en cuatro zonas de Lima. Al contrario de la hipótesis del distrito industrial, Visser encontró poca subcontratación entre las empresas de Gamarra y aún menos en los grupos de control. Según el autor, las firmas de control tenían menos acceso a la demanda final y tenían que recurrir a la 'subcontratación dependiente' con intermediarios externos. Muchas de las empresas de Gamarra tenían una excesiva capacidad productiva y continuaban manteniéndola. $\mathrm{Mu}-$ chos se integraron verticalmente, incorporando el comercio minorista en lugar de desintegrarse verticalmente. Las empresas de Gamarra sí contaban con ventajas de costos de transacción. Por ejemplo, había bajos costos de búsqueda $\mathrm{y}$ de información y era relativamente fácil copiar de los competidores. Dado el volumen de la demanda, los vendedores de las telas podían vender grandes volúmenes y ofrecer una variedad mayor. Se encontraron pocos efectos dinámicos de aprendizaje: existía poca organización de los productores, las relaciones con los gobiernos locales fueron difíciles y había bastante conflicto entre los productores (Visser, ibid.).

El número de casos es demasiado pequeño para poder establecer generalizaciones en relación a la teoría de la especialización flexible y de los distritos industriales. Sin embargo permite hacer algunas observaciones preliminares. Primero existe una gran diversidad de ti- pos de distritos industriales y formas de agrupamiento. Algunos son homogéneos en tamaño, otros son heterogéneos. Algunos agrupamientos se encontraron en algún período en camino 'hacia arriba' de la industrialización (en Brasil e Italia y otros países europeos), mientras otros estaban claramente en el camino 'hacia abajo' (México). Las mismas condiciones macroeconómicas pueden dar lugar a tendencias opuestas, como en el caso de Brasil. En el sector de zapatos el distrito adquirió características menos favorables mientras que en el agrupamiento de industria de cerámica empezó a formarse. En algunos casos la acción colectiva jugó o está jugando un papel importante mientras que es ausente en otros. En los casos de América Latina no se comprobaron todas las proposiciones centrales de la teoria: especialmente la subcontratación entre firmas pequeñas localizadas en el distrito, la profundización de la división del trabajo y el surgimiento de firmas dedicadas exclusivamente a la producción intermedia, los efectos dinámicos de los agrupamientos y de los distritos, el desarrollo de la acción colectiva de los productores y del fomento institucional.

\section{Los distritos industriales como politica}

El distrito industrial se ha desarrollado como un modelo para ser emulado. En su forma más idealizada un distrito industrial contiene ensambladoras finales, productores de componentes y piezas, proveedores de servicios y de maquinaria, firmas especializadas en diseño industrial, mercadeo, finanzas y servicios logísticos y de transporte. Las empresas pueden emprender actividades en conjunto y organizar servicios en forma colectiva para poder superar sus déficits de recursos. La acción colectiva se necesita para remediar conflictos, para la representación de sus intereses frente al 
gobierno para poder adquirir el apoyo necesario en las áreas de educación y entrenamiento, ciencia y tecnología, sea con base en la prestación de servicios públicos o en forma de asociación entre el sector público y el privado.

¿Es posible reproducir los distritos industriales y pueden éstos servir como un modelo? Según Asheim (1992) esto no sólo depende del acceso a la tecnología de especialización flexible, sino también de la existencia de empresas pequeñas capaces y de las economías de aglomeración. ¿Tienen las empresas pequeñas las competencias técnicas y profesionales? ¿Existe un número suficiente de productores en un sector para generar economías externas? ¿Se puede planificar el surgimiento de economías de aglomeración? ¿Es el gobierno capaz de estimular la acción colectiva y la asociación público-privada? También pueden darse diversas amenazas a la continuidad de un distrito. Uno es la desintegración de las instituciones locales sociales bajo el impacto de procesos (inter)nacionales de cambio social e institucional. Un distrito industrial puede desintegrarse a raíz de presiones ejercidas por firmas externas y aun firmas internas si estas últimas optan por proveedores fuera del agrupamiento. Este tipo de efectos efectivamente tomaron lugar. Cooke y Morgan (1994) analizaron el caso arquetípico de distritos de Emilia Romagna. Según estos autores, las firmas pequeñas carecían de capacidad innovadora, los aumentos en los salarios disminuyeron la competitividad y la subcontratación se está trasladando a regiones y países más baratos. La presión fiscal empujó al gobierno a racionalizar el sistema de apoyo. Para sobrevivir, las instituciones sirviendo los distritos tienen que vender sus servicios en mayor escala reduciendo su atención local. Surgieron firmas más grandes por fusiones y adquisiciones. Una de las res- puestas de las firmas pequeñas es formar consorcios.

Según Humphrey (1994), el distrito industrial como modelo tiene tres problemas importantes. Primero, que la mayoría de las definiciones se limitan a empresas pequeñas. Esto oscurece el papel jugado por firmas grandes en los distritos. El énfasis en las relaciones entre las firmas desvió la atención de la estructura interna del agrupamiento y la dinámica de las firmas. Como se vio arriba, la externalización y la subcontratación es solamente una de las respuestas a la creciente competencia e incertidumbre. Además, se asume muchas veces que existe una capacidad empresarial, la cual no existe automáticamente en muchas de las empresas pequeñas. El modelo de distrito industrial se concentra en las relaciones entre las firmas dentro del agrupamiento pero no es explícito en cuanto a las relaciones externas del distrito. Schmitz agregó que las diferencias en el tamaño de la firmas puede tener consecuencias para las características socioeconómicas de los distritos, especialmente con relación a la competencia con cooperación, acción colectiva y encaje social (Schmitz, 1994). Como también ha sido expresado por Asheim, la dinámica al interior del distrito puede alterarse cuando las firmas grandes surgen dentro del agrupamiento y se introducen desde fuera en el distrito.

¿Cuál es la dinámica de los distritos y cuáles pueden ser las posibles trayectorias de desarrollo? ¿En qué consiste la capacidad de un agrupamiento de responder a cambios externos y cuál es el papel de los agentes externos? Parece existir un entendimiento en la literatura acerca de que la apertura económica de los países en donde se encuentren expone los agrupamientos a la competencia internacional y esto es uno de los 
Teorias de desarrollo industrial regional y politicas de segunda y tercera generación

mayores cambios que los afecta. Humphrey (ibid.) introdujo, en este contexto, la noción de cadenas mundiales de productos. Estas cadenas organizan a los mercados globales y se pueden distinguir entre dos tipos: cadenas comerciales y cadenas productivas. Las cadenas productivas son coordinadas por empresas manufactureras grandes, mientras grandes casas minoristas y compañías comerciales coordinan las cadenas comerciales. Estas últimas consisten en conjuntos de redes, y algunas de ellas se extienden en distritos industriales. "La trayectoria de desarrollo de un agrupamiento es el resultado de la interacción entre firmas e instituciones del agrupamiento y otros elementos de la cadena. La inserción en una cadena crearía un potencial de desarrollo para un agrupamiento, el cual dependería tanto de su posición en la cadena como de la capacidad de las firmas e instituciones de aprovechar o crear fuentes de ventajas competitivas y oportunidades para su mejoramiento" (Humphrey, 1994:158). La forma de integración en la cadena puede variar con el tipo de cadena y con las características de la demanda de los productos.

Los estudios de caso han mostrado la importancia de los cambios en la demanda para el futuro de los agrupamientos. La cuestión sin embargo es si la demanda es el factor más importante. Igualmente críticos son la capacidad competitiva de las firmas en el agrupamiento y el desarrollo de esta capacidad a nivel del agrupamiento mismo. Esta última línea de argumentación del lado de la oferta ha sido desarrollada por Sengenberger y Pyke (1991); Spath (1991) y Pyke (1992 y 1994). Los estudios de caso han demostrado que la eficiencia dinámica a nivel del agrupamiento no se da frecuente ni fácilmente. Zeitlin (1992) sostiene también que el distrito de 'tipo italiano' es demasiado restrictivo como para servir para prescripciones de política y formuló un modelo más abierto (división de trabajo extendida entre PYMEs; servicios de apoyo industrial comunes y mecanismos locales de resolución de conflictos entre actores). La promoción de distritos industriales no significa la disolución de política nacional sino una nueva distribución de tareas entre diferentes niveles de gobierno. Las preguntas formuladas por Schmitz y por Humphrey y otros son muy relevantes para agrupamientos que ya se encuentran en una forma consolidada, pero hay otro conjunto de preguntas que se refiere a cómo surge un agrupamiento desde el inicio. La concentración geográfica puede ser una condición necesaria pero no suficiente para que surja un agrupamiento. Esta concentración atomizada debe desarrollar una división de trabajo entre las firmas.

Knorringa y Meyer-Stamer (1998) examinaron diferentes trayectorias de agrupamientos en distintas partes del mundo, tomando como base la clasificación de distritos industriales de Markusen (1996). Un agrupamiento se puede desarrollar en un 'distrito tipo italiano'. En el caso de la industria cerámica en Santa Catarina, la experiencia de la industria cerámica italiana efectivamente sirvió como modelo. Sin embargo, autores, como Cooke y Morgan y otros, tienen dudas sobre la capacidad innovadora de agrupamientos de firmas pequeñas. Una trayectoria más común es el desarrollo hacia un distrito de tipo 'rueda'. El distrito de industria zapatera en el Valle de Sinos, Brasil es un ejemplo latinoamericano. El tercer caso es la formación de un distrito o plataforma satélite en donde las PYMEs sirven como proveedoras de firmas grandes que organizan las cadenas productivas. Esta es la trayectoria menos atractiva y en el fondo no cumple con las características básicas de un distrito industrial. 
El tiempo es un factor importante. Es decir, el tiempo necesario para que los productores empiecen a interactuar y disfrutar de las economías de localización y de aglomeración. Las grandes ciudades presentan muchas veces un ambiente favorable para la difusión de información y de innovaciones. A veces son ciertos accidentes históricos y aún rurales/agrícolas que pueden explicar la formación de un distrito (por ejemplo, véase Meenu Tewari, 1998).

\section{Políticas industriales REGIONALES}

\section{A. Introducción}

El desarrollo rápido de tecnologías que permiten disminuir el espacio y el surgimiento de la competencia global en los años noventa no anunciaron el fin de las regiones. Muy al contrario: la globalización es un fenómeno intensamente localizado. Además, ciertas regiones han sido capaces de desarrollar nuevas formas de organización industrial y territorial alrededor de empresas pequeñas y medianas, las cuales lograron competir en mercados internacionales.

Surgieron nuevas prescripciones de políticas, basadas en la especialización flexible y en distritos industriales, que se comparan bien con las ideas centrales de la estrategia de 'clausura espacial selectiva' de los protagonistas más antiguos del desarrollo endógeno regional. El planteamiento central de las políticas de 'segunda generación' es que la competitividad no sólo depende de las capacidades de la empresa individual, sino también de las capacidades de sus proveedores y del entorno en que la firma opera. Los agrupamientos de firmas no sólo se benefician de las conocidas economías de aglomeración sino que también podrían profundizar la división de trabajo entre ellas mismas para compensar las desventajas de pequeña escala y para poder generar nuevas economías de alcance a través de la recombinación de gran variedad de insumos y de capacidades en nuevas maneras. La cooperación vertical entre firmas y sus proveedores refuerza la competencia entre las firmas. Los distritos industriales no son simplemente nuevas formas de organización industrial sino también son nuevas formas de organización territorial y socioeconómica. Las instituciones locales regulan y juegan un papel de apoyo. De esta manera se reconceptualizan varios aspectos del entorno empresarial.

Mientras que la especialización flexible y los distritos industriales han sido un fundamento importante de las políticas de segunda generación, es necesario señalar que otras opciones de política surgieron como respuesta a los problemas inmediatos de reestructuración local y conversión industrial. Es decir, no se crearon a partir de teorías del desarrollo industrial sino que se formaron en prácticas locales de reestructuración. Muchas veces son denominados enfoques de 'gestión local' (véase Cofey y Polese, 1985).

Esta sección está organizada de la siguiente manera: en la primera parte se revisa literatura sobre los principales temas de política, los instrumentos y los actores de las políticas de segunda generación y a continuación se presentan los planteamientos generales de las políticas de 'tercera generación'.

\section{B. Políticas de segunda generación: actores y áreas de intervención}

La literatura tiene tendencias claras con respecto a los temas centrales de política pero existen variaciones importantes 
en términos de énfasis. Las empresas nacientes del área y la cooperación entre firmas figuran de forma central. Las firmas y la inversión externa, que jugaron un papel tan importante en la 'primera generación' de políticas regionales, adquieren solamente un nivel de segunda importancia, si es que tienen alguna. La infraestructura de apoyo se enfatiza. Las políticas no deben imponerse desde arriba sino que deben ser encajadas localmente para que sean efectivas. Por último, creció el reconocimiento del papel de los gobiernos locales y regionales.

\section{Firmas, cooperación y asociación entre firmas}

Las firmas se han convertido en los actores principales de las nuevas políticas. Como punto de partida es clave que los empresarios reconozcan que su competitividad no sólo depende de ellos mismos sino también de la eficiencia de sus proveedores y del entorno en el cual operan. El elemento central de las experiencias de los distritos industriales es que las empresas responden a las oportunidades creadas por el agrupamiento y a los beneficios generados por la cooperación entre las firmas. Existen varias dimensiones de esa cooperación. La primera, la teoría del distrito industrial, postula que las firmas se especializan verticalmente en los subprocesos manufacturados y en la producción de componentes y piezas y que esto generaría economías de escala y alcance, aumentando la competitividad del agrupamiento como conjunto (Schmitz, 1992; Pyke y Sengenberger, 1994). Segundo, y muchas veces en forma implícita en la cooperación, es la noción de acuerdos de coproducción entre firmas para poder atender a contratos grandes de venta y a una complementación de líneas de productos. Una tercera dimensión de la cooperación se refiere a esfuerzos conjuntos en operaciones de mercado tales como adquisición conjunta de contratos, especialmente en mercados de exportación. En este renglón se encuentran también esfuerzos conjuntos de compra de insumos. Una cuarta área se refiere a la cooperación en la esfera de la inversión, como por ejemplo compartir activos y maquinaria y esfuerzos conjuntos en investigación y desarrollo y en diseño industrial (véase Best, 1990). Estas formas de cooperación normalmente se dan de manera selectiva entre unas pocas firmas, pero pueden desarrollarse también en forma más institucionalizada de cooperación.

La cooperación entre firmas puede ser contrastada con la visión generalizada de que los empresarios pequeños son personas individualistas y que las empresas pequeñas se encuentran aisladas en sentido estructural por la falta de acceso a información y recursos; algo que les hace difícil superar estas desventajas (Spath, 1991; Sengenberger y Pyke, 1991). Sweeney en sus extensos estudios sobre el comportamiento de la firma pequeña llega a una conclusión similar. Los empresarios pequeños tienen que cumplir con una gran variedad de tareas, y deben ser muy selectivos en términos de la información y de los contactos que establezcan con su entorno. Dependen de los contactos personales con los clientes, con los proveedores y con otros empresarios. A través de la asociación con otros pueden extender su capacidad de interacción y de aprendizaje (Sweeney, 1987). Sin embargo esto también requiere del esfuerzo personal del empresario, el cual es el factor más escaso. En otras palabras, podría ser difícil convencer a los pequeños empresarios de buscar la cooperación entre ellos mismos.

La cooperación entre firmas puede desarrollarse de distintas formas. El modelo arquetípico de distrito industrial 
(italiano) conceptualiza tal cooperación como una red horizontal entre empresas pequeñas. Estas redes pueden ser abiertas o cerradas, integrando a un grupo pequeño o a un número grande de empresas. El tamaño y el carácter de la red dependerían del propósito y de la profundidad de la cooperación misma. Por último, la cooperación entre firmas puede adquirir el carácter de acción colectiva a mayor escala y para promover los intereses generales de sus miembros. Existe poca investigación sobre el surgimiento y los papeles de diferentes tipos de asociaciones empresariales que puedan aportar criterios para la formación de estos diferentes tipos de organización. Levitsky analizó las asociaciones empresariales tanto en países en desarrollo como para países en transición hacia la economía de mercado (Levitsky, 1992, 1993, 1994). Las asociaciones empresariales son asociaciones con base en membrecía "establecidas como entidades de 'autoayuda' por empresas o grupos de empresas para promover los intereses y responder a las necesidades de sus afiliados y del sector privado en general" (1994:24). Son el vehículo más importante de la acción colectiva por parte de las firmas. Uno de los problemas que enfrentan estas asociaciones es que muchas veces no son muy representativas por la falta de miembros y además les faltan los recursos para desarrollar actividades de interés colectivo. Muchas veces las asociaciones se concentran en la promoción de los intereses de sus miembros en el plano político y desconocen su papel de servicio e información para sus miembros. La evidencia empírica demuestra que las asociaciones juegan un importante papel en la dinámica de un distrito en la mayoría de los casos.

\section{Infraestructura de las instituciones de apoyo}

La infraestructura institucional de apoyo se refiere a una variedad de servicios de apoyo a la empresa productiva (Bennett y McCoshan, 1993) y pueden ser clasificados en los siguientes grupos: servicios de guía son los servicios más elementales pero críticos; consisten en dar información a los empresarios sobre la disponibilidad de servicios de apoyo, mercados, proveedores, fuentes de financiación y de tecnología. Los servicios de entrenamiento empresarial actualmente transfieren información y conocimientos a empresas para que puedan reproducirlos. Normalmente se dan en forma estandarizada, a través del intercambio de información y entrenamiento. El tercer tipo se llama asesoría de negocios para el desarrollo de mercados o de tecnología. Consiste en transferencia de información y conocimientos en forma ajustada a la empresa individual. Los servicios de asistencia empresarial se refieren a servicios de apoyo que actúan para la firma. Por último, el apoyo empresarial se refiere a la asistencia directa proveyendo suministros específicos a la firma (Bennett y McCoshan, 1993).

En la medida en que se extiende la apertura de países y los mercados domésticos se someten a una mayor competencia, el entorno de la firma se vuelve más volátil. Los empresarios deben absorber información constantemente sobre estos cambios. Los servicios de información se vuelven más importantes para poder formular respuestas adecuadas. Tipicamente son las asociaciones generales, tales como cámaras de comercio, asociaciones sectoriales y clubes empresariales locales los que juegan un papel relevante en prestar servicios de guía. 
En cuanto a los servicios de apoyo empresarial, Levy observó que "existe muy poca investigación sobre la naturaleza y efectividad de las intervenciones colectivas (de gobierno, de las asociaciones y de ONGs) en el desarrollo de sistemas de apoyo" (Levy, 1994:3/4). Su propia investigación sobre países como Corea, Japón, Indonesia y Colombia ha generado algunas indicaciones para la política con relación al mercadeo de exportación, servicios tecnológicos y financieros. Concluyó que en todos los casos estudiados las fuentes privadas (como de compradores/comerciantes, de empresas similares, de firmas contratantes y de sus propias asociaciones empresariales) se prefieren sobre todo a servicios colectivos públicos. Los beneficios de estos últimos varían entre las PYME (pequeña y mediana empresa) según sus recursos económicos propios. Los mecanismos de apoyo colectivo son importantes especialmente al inicio de un proceso de crecimiento de las exportaciones y son efectivos cuando son descentralizados y complementarios a los servicios privados de apoyo. Best presentó ejemplos de cooperativas crediticias, consorcios para garantizar préstamos y para mercadeo en varias de las regiones de la 'tercera Italia' (Best, 1990).

Otro aspecto es el de los servicios empresariales comerciales, tales como servicios financieros (cobro de cuentas, contabilidad), servicios de diseño industrial, de mantenimiento e ingeniería, servicios legales y logísticos y de compra de insumos. Las firmas grandes que adoptan métodos flexibles de producción frecuentemente externalizan una parte de sus servicios empresariales. Al mismo tiempo hay muchas otras firmas que son demasiado pequeñas para poder internalizar estos servicios en alguna forma (Cofey y Bailly, 1991; Cofey, 1992; Goe, 1991). En este contexto, Hansen enfatizó en la importancia de estos ser- vicios para el desarrollo regional y local (Hansen, 1994).

La prestación de servicios de apoyo puede ser más eficiente dirigiéndose a redes y agrupamientos. "La capacidad de las firmas locales de enfrentar nuevas demandas, muchas veces depende del apoyo que brindan las instituciones locales y de la base de fondo de la cooperación entre las firmas mismas (relaciones de parentesco e interacción social fuerte). Si las instituciones locales (públicas y privadas) son fuertes, el agrupamiento puede extenderse hacia nuevos nichos de mercado, extender el espacio de sus actividades dentro de la cadena productiva o desarrollar nuevos vínculos con el mercado final" (Humphrey y Schmitz, 1996:1867).

La literatura sobre distritos industriales nos presenta algunos ejemplos importantes para ser mencionados. Con base en su revisión de casos europeos de distritos industriales Schmitz y $\mathrm{Mu}-$ syck (1994) y Pyke (1992 y 1994) enfatizan la importancia de desarrollar la capacidad tecnológica de las firmas, encontrar nuevos mercados, entrenar su staff y captar capital. Los bancos locales jugaron un papel importante para los distritos y tienen un mejor conocimiento del desarrollo de los agrupamientos locales que los bancos nacionales e internacionales. La autogestión y las garantías para el crédito han sido importantes en algunos de los casos. El entrenamiento no sólo se refiere a los trabajadores sino también a los empresarios mismos. En todos los casos el sector privado jugó un papel en la definición de los programas, su cofinanciación y su ejecución, mientras que los gobiernos jugaron un papel complementario. En cuanto a servicios de apoyo al mercadeo, tanto los gobiernos como las asociaciones empresariales jugaron algún papel. Algunos ejemplos importantes fue- 
ron el CITER en Emilia Romagna en Italia y la Fundación Steinbein en BadenWurtemberg, Alemania, que tiene unos 300 puntos de transferencia para poder llegar a las empresas medianas y más pequeñas. Un caso importante de desarrollo de redes fue el del Instituto Tecnológico de Dinamarca. Las empresas pequeñas y medianas no estaban suficientemente equipadas para poder enfrentarse con los retos de la creciente competencia internacional. Se vio la formación de redes como una manera de poner grupos de empresarios en contacto con nuevos productos y nuevas tecnologias. Las redes también sirvieron para que los empresarios desarrollaran nuevos productos, pusieran nuevos agentes representantes y sistemas de distribución en nuevos mercados, conformaran sus productos en mayores conjuntos de productos. Así, las firmas pudieron superar obstáculos que difícilmente podían superar individualmente. La asistencia externa jugó el papel de mediador y facilitador de la red y los fondos públicos fueron usados para generar apoyo financiero privado y adicional (Humphrey y Schmitz, 1996).

Varios comentaristas han observado que la cooperación entre firmas no se desarrolla fácilmente. Por ejemplo, Pyke (1994) concluyó con base en las experiencias europeas: "Una de las lecciones comunes de todas las iniciativas es que la cooperación entre empresas pequeñas requiere de un catalizador externo o mediador" (Pyke, 1994:121). Varios autores han mencionado la importancia de una estrategia local regional para integrar los esfuerzos y para conceptualizar los distritos industriales como un nuevo modelo de desarrollo local regional basado en: delegación de funciones hacia una gran variedad de organizaciones intermedias y a los gobiernos locales y de utilizar instituciones cercanas a las empresas, enfatizando la autogestión y organización del sector privado y con base en una concertación local sobre la dirección de desarrollo económico (Sengenberger y Pyke, 1991; Schmitz y Musyck, 1994).

\section{Encaje local social}

Es importante señalar que en los tiempos actuales de competencia global en la cual la competencia se extiende a todas las esferas de transformación y transacción, el encaje local social se ha vuelto un tema corriente. Hay diferentes razones que pueden explicar esto. Primero, las relaciones locales sociales constituyen redes de seguridad que permiten a los empresarios tomar riesgos e innovar en productos y mercados. Por ejemplo, en el caso de la Tercera Italia se hace referencia a las estructuras familiares tradicionales que crearon un sistema de apoyo mutuo (Piore y Sabel, 1983). En segundo término, el encaje local social permite una interacción social intensa, intercambio de información y difusión más rápida de innovaciones (Visser, 1996). Son precisamente conocimientos tácitos que se adquieren en esta forma. Tercero, la historia y la cultura de un territorio generan valores comunes y códigos de comportamiento social que, a su vez, contribuyen a formar confiabilidad situacional entre los empresarios y esto prepara la base para la colaboración entre las firmas (Knorringa, 1996). La confiabilidad también disminuye los costos de transacción ya que las firmas necesitan gastar menos esfuerzo y costo en investigar a los contratantes potenciales, formular los contratos y preparar posibles contingencias. En cuarto lugar, la existencia de una identidad local contribuye a formar la base para la concertación y resolución de conflictos sobre las prioridades para el desarrollo económico local y sobre los cursos de acción pública, colectiva y privada. La creación de un ambiente más conducen- 
te a la concertación y a la autorregulación local son temas importantes de política.

\section{Gobiernos locales y desarrollo económico local}

En el período del estado de bienestar y del estado desarrollista los gobiernos locales se concentraron en la prestación de algunos servicios básicos y en la planificación física. Su rol en gestionar $\mathrm{y}$ promover el desarrollo económico local fue bastante limitado. Existen varios factores que han contribuido a que los gobiernos locales empezaran a jugar un papel más prominente. Primero, los procesos de reestructuración industrial provocaron pérdidas masivas en empleo dentro de las regiones más industrializadas. Las crisis económicas a finales de los años setenta y al principio de la década de los ochenta hicieron sentir muy fuertemente estos impactos. Los gobiernos locales respondieron con formas de gestión de emergencia. Un segundo factor fueron las tendencias hacia la descentralización en el sector público, las cuales a su vez tuvieron múltiples causas (Helmsing, 1996). Ciertas responsabilidades públicas se transfirieron a los gobiernos locales. La necesidad de generar más ingresos fiscales obligó a los gobiernos locales a preocuparse más por el desarrollo económico de su área. En muchos países se aprobaron nuevas legislaciones que permitieron a los gobiernos locales entrar en asociaciones con el sector privado. El tercer factor ha sido el cambio en las percepciones de seguridad social (de subsidios al ingreso a creación de empleo) que contribuyó a que los gobiernos locales se dedicaran a estimular la creación de empleo local (Bennett, 1990). Cuarto, en algunos países los gobiernos centrales formularon programas que facilitaron que los gobiernos locales se volvieran más activos en la promoción del desarrollo económico local. La Unión Europea desde hace muchos años ha jugado un papel importante en el desarrollo económico local regional a través de sus fondos estructurales (Fondo Estructural Regional) y programas temáticos (por ejemplo el programa ADEL (Acciones de Desarrollo Económico Local) y los Planes Tecnológicos Regionales) (PTRS) y las estrategias regionales de innovación. Finalmente, las experiencias de los distritos industriales han dado una mayor credibilidad a los gobiernos locales y regionales en materia de desarrollo económico especialmente en cuanto a la regulación económica, infraestructura, parques industriales, vivienda social, entrenamiento.

La responsabilidad principal de los gobiernos locales se refiere a la infraestructura física, la preparación de terrenos y la planificación del uso del suelo. Además los gobiernos locales normalmente tienen un papel importante en la prestación de los servicios básicos. Por lo general, los gobiernos locales también en los países avanzados gastan una proporción muy pequeña de sus presupuestos en actividades directamente ligadas a la promoción de desarrollo económico local. Más importante, sin embargo, es la manera en que se realizan las funciones básicas y se entiende el significado económico de aquellos en términos de: a) ser una fuente de oportunidades económicas, $\mathrm{y} b$ ) como servicios cuya prestación puede dificultar o contribuir al desarrollo empresarial y a la competitividad de las empresas (Bennett y McCoshan, 1993).

Los estudios sobre especialización flexible reconocen al papel de los gobiernos locales y regionales, especialmente los estudios hechos a mediados de los años 80. Por ejemplo, Brusco y Righi (1989) documentan casos en donde los gobiernos locales y provinciales en el nordoeste de Italia establecieron parques 
industriales, ofrecían préstamos a empresas pequeñas y divulgaban información sobre nuevas tecnologías y mercados en sectores particulares. En muchas instancias los gobiernos locales ofrecían capital de semilla para proyectos. Sin embargo, los autores expresan cierta cautela cuando subrayan que raramente el gobierno local jugó un papel decisivo en el desarrollo de los agrupamientos. Esto ha sido confirmado por otros autores para otros casos (Schmitz, (1992 y 1994); Meyer-Stamer (1998); Visser (1996).

Una contribución útil, desde la perspectiva de la gestión local del desarrollo, proviene de Blakely. Según este autor, existen cuatro tipos de opciones estratégicas. El primero se refiere al desarrollo de la localidad, en términos de su ambiente físico. El segundo se refiere a estrategias empresariales, sobre todo a través de la formación de nuevas empresas y de atraer nueva inversión al área. El tercer tipo trata del desarrollo de los recursos humanos locales que se refiere a la empleabilidad de la fuerza de trabajo local en mercados laborales crecientemente flexibles. El cuarto se refiere al desarrollo económico comunitario (Blakely, 1989). Este último tiene mucha semejanza con los programas de microempresa y del sector informal, pero también contiene elementos del desarrollo alternativo y de la economía social.

\section{Politicas de tercera generación}

Actualmente estamos virando hacia una tercera generación de políticas de industrialización local regional. Esta tercera generación es, en parte, una respuesta al estudio continuado y la evaluación del desarrollo y de la política regional endógena. Por otra parte, estas nuevas políticas surgen del reconocimiento de que la globalización hace que sistemas terri- toriales de producción compitan entre sí mismos y no solamente lo hagan las firmas. Esto significaría que las políticas no pueden ser exclusivamente locales o regionales, sino que deben tomar en cuenta la posición y el posicionamiento de los sistemas territoriales dentro de contextos nacionales e internacionales. Las políticas no pueden ser únicamente locales hasta el punto de excluir o desconocer las políticas sectoriales e (inter)nacionales, ni puede excluir o desconocer el papel de la firma y la inversión externa. No sólo se requiere la cooperación entre las firmas, sino también entre las instituciones de apoyo. La coordinación horizontal entre un número de actores locales (que fue el objeto de las políticas de segunda generación) debe ser complementada por la coordinación entre niveles. Por último, las políticas de tercera generación se basan en el reconocimiento de que nuevas políticas no necesitan más recursos sino buscar mejorar la 'racionalidad sistémica' en el uso de los recursos existentes, a través de la concertación y la convergencia más que por la via de la coordinación burocrática.

Las políticas de tercera generación se distinguen de las de segunda generación en la medida en que las instituciones regulatorias y de apoyo deben entender que la capacidad competitiva de los sistemas regionales de producción no sólo depende de las firmas y sus proveedores sino también de las condiciones básicas en el entorno externo.

\section{Agentes externos y el manejo del nexo externo}

Las empresas multinacionales y la inversión extranjera directa son agentes importantes de cambio. La literatura sobre los distritos industriales básicamente desconoce esta categoría de agentes de cambio ya que se concentró en la empresa local pequeña. La visión con- 
vencional en la teoría del desarrollo regional sobre la empresa multinacional y la inversión extranjera sigue siendo dominada por las proposiciones de 'la planta subsidiaria'. Es decir, aunque las plantas subsidiarias establecidas por los inversionistas externos pueden contribuir a aliviar el desempleo en las regiones periféricas, no es muy probable que contribuyan al desarrollo económico a más largo plazo. Más bien es muy probable que estos efectos sean negativos en términos de propiedad y control, falta de capacidad innovadora y de baja en los niveles de calificación de sus trabajadores. Las casas matrices tienden a prohibir el desarrollo de vínculos locales y las plantas se encuentran insertas en redes productivas externas.

Varios autores han empezado a explorar en qué medida el desarrollo de nuevas tecnologías, especialización flexible y la competencia 'nueva' cambiaría estas proposiciones. En una revisión extensiva de la literatura, principalmente sobre la inversión multinacional y con relación a Europa, Young y otros (1994) llegaron a la conclusión de que bajo ciertas condiciones la empresa multinacional podría ser un instrumento para el desarrollo económico regional. Agregaron cuatro implicaciones de política. Primero, enfatizan la necesidad de un enfoque regional integrado de política de desarrollo regional en donde la tecnología más que la inversión en sí es el motivo principal. Las empresas multinacionales pueden contribuir a establecer agrupamientos sectoriales y tecnológicos fuertes bajo la condición de que se creen vínculos con universidades locales y centros de investigación y vínculos hacia atrás con empresas locales. Segundo, esto requiere una política de búsqueda selectiva de inversión multinacional y un seguimiento continuado para asegurar que surja un encaje local. Un tercer punto que es importante entender es cuáles son los factores de localización de inversión multinacional y qué son los factores de atracción de un área como localización de inversión multinacional. Finalmente, los autores subrayan la importancia de que las empresas multinacionales tengan gerentes empresariales.

Estos puntos encuentran sustento y son desarrollados más por Barquero (1997) quien planteó que existía una convergencia (potencial) entre las estrategias de las multinacionales por un lado y las estrategias de ciudades y regiones por el otro. Señaló que las empresas multinacionales mismas han cambiado sus estrategias. Es decir, ya no tienen una configuración tradicional jerárquica entre casa matriz y planta subsidiaria. Las nuevas formas de organización crean en las subsidiarias mayores niveles de autonomía operacional para poder integrarse localmente. En mercados altamente competitivos las plantas subsidiarias necesitan redes de provisión de insumos de tipo JAT (justo a tiempo) y requieren una interacción directa e intensa con proveedores. En su búsqueda por localizaciones alternativas, las empresas multinacionales ya no están tan preocupadas por ventajas generales de costo y otras ventajas generales que se presentan en muchas regiones, sino por ventajas específicas de una localización particular, tales como provenientes de su agrupamiento económico (estructura industrial), recursos particulares y otras ventajas no tangibles.

Las trayectorias de crecimiento de agrupamientos de firmas pueden ser alteradas por la llegada de agentes externos. Los agrupamientos actualmente atraen a agentes externos, tales como casas comerciales y comerciantes internacionales. Varios de los estudios de caso mostraron que esta llegada puede tener efectos mixtos sobre el agrupa- 
A. H. J. (Bert) Helmsing

miento. Puede alterar la estructura de demanda y puede generar ventajas a favor de las firmas grandes y no a las empresas pequeñas, resultando en una diferenciación interna del agrupamiento. Humphrey y Schmitz (1994), en su trabajo ya citado, exploraron las implicaciones de diferentes tipos de cadenas productivas globales sobre el crecimiento de los agrupamientos. A veces las firmas dentro del agrupamiento operan en diferentes segmentos de mercado y por tanto un cambio en la estructura de demanda no afectaría a todas las firmas. En otros casos los agrupamientos han sido exitosos en su respuesta y desarrollaron sus propios nexos externos. Por ejemplo, a través de organizar su propia marca, con niveles de calidad especificada y con su propia organización del mercadeo, pequeños productores de mármol en Macael fueron capaces de deshacerse de su aislamiento y desarrollar una posición en el mercado nacional e internacional. Una agencia nacional jugó un papel importante como catalizador (Barzelay, 1994).

El acceso a mercados externos es muchas veces indirecto porque depende de firmas y comerciantes intermediarios (nacionales o extranjeros) y de firmas en los mercados externos. Se sabe relativamente poco de la importancia de estas opciones de vínculos al mercado. Puede referirse a subcontratación comercial, como en el agrupamiento de calzado de Agra, India (Knorringa, 1996), o puede ser constituido por vínculos comerciales entre redes de pequeños productores y firmas intermediarias grandes. Yung Whee Rhee y otros (1989) documentaron el caso de las casas comerciales pequeñas de exportación de Hong Kong. Estas empresas compraron directamente de exportadores indirectos (sin subcontratación y/o comisión) y jugaron un papel en el control de calidad y diseño de productos. Clave para su éxito ha sido su conocimiento profundo de los nichos de mercado en determinados países. El desarrollo de nuevos mercados requiere un esfuerzo persistente sobre un período de tiempo, y esto está muchas veces por encima de los recursos y capacidades de las empresas pequeñas. Se necesita apoyo de un nivel mayor. Una opción es la acción colectiva, al nivel de un agrupamiento, o de un red de empresas igualmente articuladas que forman un consorcio o desarrollan acción colectiva a través de su asociación empresarial. Otra opción es recurrir al nivel nacional con una iniciativa sectorial. Esto nos lleva a la segunda dimensión importante de las políticas de tercera generación.

\section{Nuevas formas de gobernabilidad: redes de politica}

En su libro sobre la "nueva competencia' Michael Best ha sido el protagonista de un nuevo tipo de política industrial. Según este autor, una política industrial debería promover competencia de tipo schumpeteriano y firmas más empresariales. Esto significaria, entre otras cosas, formar mercados y buscar influenciar la forma que toma la competencia de tal modo que conduzca a un mejor desempeño económico. Estaría basada en: a) una política pro-competencia y antimonopolio; $b$ ) promover redes entre empresas y preservar un balance entre competencia y cooperación; $c$ ) dar prioridad a una estrategia de planificación que sea el resultado de la concertación con líderes industriales, y no de un diseño de planificadores, por ejemplo a través de asociaciones sectoriales, $d$ ) no tratar de 'seleccionar ganadores' sino mantener una orientación sectorial abierta. Las políticas sectoriales están en menor grado sujetas a politiqueo de intereses específicos, más plegadas al consenso y la responsabilidad mutua para formular e implementar estrategias sec- 
toriales (Best, 1990). Existen diferencias en la literatura en términos de quienes deben participar en los procesos de política industrial. Best menciona a dos (gobierno y líderes industriales), otros, como Sengenberger y Pyke son partidarios de políticas tripartitas, incluyendo a los sindicatos. Bennett y McCoshan (1993) van más allá y mantienen que el reto principal es desarrollar una mayor racionalidad sistémica entre todos los actores involucrados. Un consenso nacional sobre prioridades de industrialización debe ser un proceso inclusivo, teniendo en cuenta no sólo a los ministerios directamente responsables y a las asociaciones nacionales de industria, sino que debería incluir la participación de los sectores y agencias que generan insumos importantes en el entorno de la industria (es decir, las condiciones básicas en términos de infraestructuras físicas, económicas -inclusive el sistema de apoyo a la empresa- y social. Una pregunta clave, no resuelta aun, es ¿en qué forma se incorporan los agrupamientos y distritos industriales, a través del sector o a través de instituciones territoriales?

Meyer-Stamer (1997) discutiendo el proceso de cambio industrial en el Brasil, llega muy cerca a lo formulado por Bennett y McCoshan cuando plantea la noción de 'competitividad sistémica': "competitividad industrial sostenida, depende no sólo de las capacidades (a nivel micro) de las firmas y de un marco macroeconómico estable, sino también y sobre todo de un tejido de instituciones de apoyo de sectores específicos y de políticas enfocadas (del nivel meso) y de unas estructuras de gobernabilidad que facilitan la resolución de problemas entre el Estado y los actores de la sociedad (nivel meta)" (Meyer-Stamer, 1997: 369). El Estado debe funcionar como un coordinador, moderador y comunicador en redes de política con firmas, sus asociaciones, las organizaciones intermedia- rias en ciencia y tecnología y entrenamiento y con los sindicatos. Las redes deben funcionar, según este autor, como foros abiertos de política no exclusivamente gubernamentales. Las redes exitosas de política dependen, entre otros, de la autonomía de los actores colectivos que son capaces de resolver conflictos internos de interés; que tienen confianza y un compromiso con un justo intercambio, que tienen una orientación hacia resultados substantivos, un proceso de toma conjunta de decisiones, intercambio de información y que están basadas en la reciprocidad.

\section{Redes de desarrollo económico local}

Meyer-Stamer (1997) enfoca el problema desde el nivel nacional y discute cómo las redes nacionales pueden ser descentralizadas. Bennett y McCoshan (1993) toman una posición diferente. Según estos autores, la clave es la coordinación local de la acción. Aunque muchos sistemas de apoyo son organizados al nivel nacional por razones de escala y eficiencia y no pueden ser descentralizados completamente, la implementación casi siempre ocurre localmente. Por esta razón las redes deben ser organizadas localmente. Las redes de Desarrollo Económico Local (DEL) "tienen el propósito de integrar programas verticales y facilitan los flujos de información sobre oportunidades y sobre recursos necesarios para aprovecharlas". Las redes facilitan la internalización de externalidades de la toma de decisiones económicas a través de un mejor afinamiento de las decisiones, buscando prevenir externalidades negativas y promover las positivas. Los autores distinguen varios tipos de redes (redes fragmentadas, jerárquicas, focalizadas, de matrices y de tareas flexibles) y examinan la dinámica del desarrollo de redes. Encuentran que la capacidad de establecer y desarrollar re- 
A. H. J. (Bert) Helmsing

des de DEL varía mucho por región, dependiendo de la diversidad de sus estructuras económicas y del nivel de desarrollo económico, así como de factores históricos explicando la densidad de las instituciones locales.

En su estudio de 33 redes de DEL y asociaciones públicas-privadas apoyadas por el programa ADEL de la UE, Bennett y Krebs (1994) concluyeron que "parece que surgen contrastes entre redes a través de las etapas de desarrollo de los proyectos de DEL. El liderazgo del gobierno ha sido importante en todas las etapas, mientras que agencias de desarrollo con fines específicos y los agentes locales jugaron un papel de catalizador y llenaron vacíos" (Bennett y Krebs, 1994:139). La estructura del liderazgo local es un determinante crucial de las redes locales: mientras más diferenciada la economía y la sociedad local, menos integradas serán sus actividades colectivas. Las regiones más exitosas han logrado crear estructuras coordinadas de gobernabilidad local. Sus redes son similares a las encontradas en los distritos industriales de Italia. Los autores anotan que el desarrollo de redes covaría con niveles de desarrollo: las regiones estancadas y decrecientes tienen redes fragmentadas y separadas entre sí (como una configuración de mosaico). El gobierno central juega un papel más prominente en el desarrollo de proyectos y su financiación en las regiones menos desarrolladas o estancadas que en las regiones más desarrolladas.

Para concluir, las políticas de tercera generación enfatizan la competitividad sistémica mientras las políticas de segunda generación se orientan hacia las acciones de las firmas y la cooperación entre las firmas; así, las políticas de tercera generación enfatizan la importancia de las condiciones básicas. Estas útimas no sólo se refieren al marco macroeconómico, sino también a un conjunto de acciones del nivel meso (sector y local) reforzando la competitividad de sistemas regionales de producción. Estos sistemas regionales de producción no se limitan a agrupamientos de pequeñas empresas, como en muchos estudios de distritos industriales. Las condiciones básicas también están fuera del control de la mayoría de las firmas grandes y estas firmas también dependen del mejoramiento de estas condiciones. Y para las empresas pequeñas los vínculos con firmas grandes pueden constituir un camino más rápido para la adquisición de innovaciones y competitividad. Las políticas de tercera generación enfatizan no solamente en la formación de redes entre firmas sino también entre las instituciones de apoyo para poder generar una mayor racionalidad sistémica del esfuerzo total. Los sistemas de gobernabilidad industrial están compuestos de múltiples niveles. El éxito de una localidad o región depende en gran medida de la manera como movilice el nexo vertical, ganando acceso a programas nacionales e internacionales.

\section{Algunas observaciones finales}

En los últimos años el análisis del desarrollo económico localizado se ha puesto en el centro de los debates del desarrollo económico. Muchos de los nuevos impulsos a la teoría del desarrollo regional y local fueron aportados por analistas quienes no tenían una historia profesional en este campo científico. Más aún, recientemente economistas del comercio internacional empezaron a interesarse por 'la economía geográfica' (Krugman, 1991). Estas tendencias han contribuido a un enriquecimiento de nuestro campo de estudio.

La base del renacimiento de las políticas de segunda generación ha sido el 
Teorias de desarrollo industrial regional y politicas de segunda y tercera generación

análisis del comportamiento a nivel de la empresa y la organización industrial a nivel del distrito industrial y tuvo una orientación fuertemente económica. Las bases de las políticas de tercera generación tienen un enfoque más bien institucional del desarrollo económico localizado. El estudio de la competitividad se ha trasladado de tecnología de maquinaria hacia tecnología de conocimientos y aprendizaje colectivo. La tercera generación pone más énfasis en las 'condiciones básicas', el aprendizaje colectivo, el encaje social y el nexo externo. Por último, la tercera generación de política no sólo responsabiliza a actores locales individuales (empresarios, asociaciones, y gobiernos locales). Zeitlin (1992) mantiene también que el distrito de 'tipo italiano' es demasiado restrictivo como para servir para prescripciones de política y formuló un modelo más abierto (división de trabajo extendida entre PYMEs; servicios de apoyo industrial comunes, y mecanismos locales de resolución de conflictos entre actores).

La promoción de distritos industriales no significa la disolución de política nacional sino una nueva distribución de tareas entre diferentes niveles de gobierno. Las nuevas formas de gobernabilidad industrial no se restringen al nivel local, sino también asignan responsabilidades a actores nacionales e internacionales. Actores y agencias nacionales, públicas y privadas, deben jugar un papel impulsor especialmente para regiones periféricas que carecen de capital económico, social y fisico para emprender el desarrollo económico.

\section{BiBLIOGRAFÍA}

Asheim, B.T. 1992. "Flexible specialisation, industrial districts and small firms: a critical appraisal”. En: Ernste, H. \& Meier, V. eds. 1992. Regional development and contemporary industrial response: extending flexible specialisation. London: Belhaven Press. Pp. 45-56.

Amin, A. \& Thrift, N. 1994. Globalization, institutions and regional development in Europe. Oxford: Oxford University Press.

Barquero, A. V. 1997. "Gran empresa y desarrollo endógeno. La convergencia estratégica de las empresas y territorios ante el desafío de la competencia”. Revista EURE, 23, 70, 5-18.

Bennett, R. J. \& McCoshan, A. 1993. Enterprise and human resource development. Local capacity building. London: Paul Chapman.

Bennett, R. J. \& Krebs, G. 1994. "Local economic development partnerships: an analysis of policy networks in ECLEDA local employment development strategies". Regional studies, 28, 2, 119-140.

Best, M. H. 1990. The new competition. Institutions of industrial restructuring. Cambridge: Polity Press.

Brusco, S. 1989. "A policy for industrial districts". En: Goodman, E. \& Bamford, J. eds. 1989. Small firms and industrial districts in Italy. London: Routledge. Pp. 259-269

Brusco, S. \& Righi, E. 1989. "Local government, industrial policy and social consensus: the case of Modena (Italy)", Economy and Society, 18, 406-424.

Carlton, D. W. \& Perloff, J. M. 1992. Modern industrial organisation. New York: Harper Collins

Cofey, W. \& Bailly, A. 1991. "Producer services and flexible production: an exploratory analysis". Growth and Change, 22, 4, 95-117. 
Cofey, W. J. 1992. "The role of producer services in systems of flexible production”. En: Ernste, H. \& Meier, V. eds. 1992. Regional development and contemporary industrial response: extending flexible specialization. London: Belhaven Press. Pp. 3-24.

Cooke, P. \& Morgan, K. 1994. "Growth regions under duress: renewal strategies" in Baden-Wurtemberg and Emilia-Romagna. En: Amin \& Thrift, eds. 1994. Pp. 91-117.

De Mattos, C., A., Guerra M. y M. Riveros M, F. 1994. "Reestructuración, crecimiento industrial y concentración en Chile, 1985-1991". Santiago: Instituto de Estudios Urbanos, Pontificia Universidad Católica de Chile. Documentos de Trabajo No. 175.

Dicken, H. 1990. Global shift. London: Sage Publications

Echeverri-Carroll, E., Hunnicutt, M. \& Hansen, N. 1998. "Do asymmetric networks help or hinder small firm's ability to export?". Regional Studies, $32,8,721-733$.

Friedmann, J. \& Douglass, M. 1978. "Agropolitan development: towards a new strategy for regional development in Asia”. En: Fu Chen Lo \& Kamal Salih, eds. 1978. Growth pole strategy and regional development policy. Oxford: Pergamon/Nagoya: UNCRD pp 163-192.

Goe, W. R. 1991, "The growth of producer service industries: sorting out the externalization debate". Growth and Change, Fall, 118-141.

Hansen, N. 1994. "The strategic role of producer services in regional development”. International Regional Science Review, 16, 187-195.

Helmsing, A. H. J. 1996. "South Africa: post-Apartheid restructuring of government - which way? Reflections on international experiences". En Helmsing A. H. J. et al. (eds.) 1996. Restructuring the state and intergovernmental fiscal relations in South
Africa. Johannesburg: FES in association with the Graduate School for Public \& Development Management. University of Witswatersrand. Pp. 2548.

Helmsing, A. H. J. 1998. "Survey of economic restructuring and competitiveness of manufacturing industries, Armenia, Manizales and Pereira, Colombia, 1993-1996". Research report. The Hague: Institute of Social Studies (mimeographed).

Helmsing, A. H. J. 1998. "Survey of economic restructuring and competitiveness of manufacturing industries, Bulawayo, Zimbabwe, 1992-1995". Research report. The Hague: Institute of Social Studies (mimeographed).

Humphrey, J. 1995. "Industrial organisation in developing countries: from models to trajectories". World Development, 23, 1, 149-162.

Humphrey, J. \& Schmitz, H. 1996. "The triple C approach to local industrial policy". World Development, 24, 12, 1859-1877.

Knorringa, P. \& Weijland, H. 1993. "Subcontracting - the incorporation of small producers in dynamic industrial networks". En: Baud, I.S.A. \& De Bruijne, G. A. eds. 1993. Gender, small scale industry and development policies. London: IT Publications, Pp. 35-46.

Knorringa, P. 1996. The economics of collaboration. New Delhi: Sage Publications

Knorringa, P. \& Meyer-Stamer, J., 1998. "New dimensions in local enterprise cooperation and development: from clusters to industrial districts". En: UNCTAD, 1998. New approaches to science and technology cooperation and capacity building. Geneva/New York: UNCTAD, Pp. 31-55.

Kristensen, P. H. 1992. "Strategies against structure: institutions and economic organization in Denmark". En: Whitley, R. ed. 1992. European 
Teorias de desarrollo industrial regional y políticas de segunda y tercera generación

business systems: firms and markets in their national context. London: Sage. Pp. 117-136.

Krugman, P. 1991. Geography and trade. Leuven: Leuven University Press.

Levitsky, J. 1992. "Private sector membership associations and support for SMEs". Small enterprise Development, $3,1,22-34$.

Levitsky, J. 1993. "Private sector organisations and support for small and microenterprises”. En: Helmsing, A. H. J. \& Kolstee, Th. Eds. 1993. Small enterprises and changing policies. London: IT Publications.

Levitsky, J. 1994. "Business associations in countries in transition to market economies". Small enterprise Development, 5, 3, 24-34.

Levy, B. 1994. Succesful small and medium enterprises and their support systems: a comparative analysis of four countries. Washington: World Bank.

Lovering, J. 1990. "Fordisms unknown successor: a comment on Scott's theory of flexible accumulation and the rer-emergence of regional economies". International Journal of Urban and Regional Research, 14.1.159-175.

Maillat, D., 1998. "Innovative milieux and new generations of regional policies". Entrepreneurship \& Regional Development, 10, 1-16.

Markusen, A. 1996. "Sticky places in slippery space: a typology of industrial districts". Economic geography, 72, 293-314.

Meyer-Stamer, J. 1997. "New patterns of governance for industrial change: perspectives from Brazil". Journal of Development Studies, 33, 3, 364-391.

Meyer-Stamer, J. 1998. "Path dependence in regional development: persistence and change in three industrial clusters in Santa Catarina, Brazil". World Development, 26, 8, 1495-1511.

Milne, J. 1991. "Small firms, industrial organisation and space: the case of the UK high fidelity audio sector".
Environment \& Planning, A, 23, 6, 779932.

Morgan, K. 1997. "The learning region: institutions, innovation and regional renewal". Regional Studies, 31, 5, 491503.

Pedersen, P. O., Sverisson, A. \& Van Dijk, M. P. eds. 1994. Flexible specialisation. The dynamics of small scale industries in the South. London: Intermediate Technology Publications.

Piore, M. \& Sabel, Ch. 1984. The second industrial divide: possibilities for prosperity. New York: Basic Books.

Popkin, S. L. 1981. "Public choice and rural development: free riders, lemons and institutional design”. En Russell, C. S. et al. eds. Public choice and rural development. Washington: Resources for the Future. Pp. 43-80.

Porter, M. E. 1990. The competitive advantage of nations. New York: The Free Press.

Pyke, F. 1992. Industrial development through small firm cooperation - theory and practice. Geneva: ILO.

Pyke, F. 1994. Small firms, technical services and inter-firm co-operation. Geneva: ILO.

Rabellotti, R. 1995. "Is there an 'Industrial District Model'? Footwear districts in Italy and Mexico compared". World Development, 23, 1, 29-41.

Rakowski, C. A. 1994. "Convergence and divergence in the informal sector debate: a focus on Latin America, 19841992". World Development, 23, 4, 501516.

Sengenberger, W. \& Pyke, F. 1991. "Small firm industrial districts and local economic regeneration: research and policy issues". Labour and Society, $16,1,1-25$.

Scott A. J. \& Storper, M. 1992. "Regional development reconsidered". En: Ernste, H. \& Meier, V. eds. 1992. Regional development and contemporary industrial response: extending flexible 
specialization. London: Belhaven Press. Pp. 3-24.

Scott, A. J. 1988. "Flexible production systems and regional development: the rise of new industrial spaces in North America and Europe". International Journal of Urban and Regional Research, 12, 2, 171-187.

Schmitz, H. 1992. "Industrial districts: model and reality in Baden-Wurtemberg, Germany". En: Pyke, F. \& Segenberger, W. comps. Industrial districts and local economic regeneration. Ginebra: IILS. Pp. 87-121.

Schmitz, H. 1995. "Small shoemakers and fordist giants: tale of a supercluster". World Development, 23, 1, 9-28.

Schmitz, H. \& Musyck, B. 1994. "Industrial districts in Europe: policy lessons for developing countries?" World Development, 22, 6, 889-910.

Schmitz, H. 1995. "Collective efficiency: growth path for small scale industry". Journal of Development Studies, 31, 4, 529-561.

Smith D. 1976. Industrial location theory. London: Methuen.

Spath, B. 1991. "Collective efficiency of small firms and the institutional environment. EADI workshop on flexible specialisation and industrialisation in the Third World". Copenhagen: Center for Development Research.

Stohr, W.B. \& Taylor, F. D. R. eds. 1981. Development from above or below? Dialectics of regional planning in developing countries. London: John Wiley.

Storper, M. 1990. "Industrialization and the regional question in the Third World: lessons of post-imperialism; prospects of post-Fordism". International Journal of Urban and Regional Research, 14, 3, 423-445.

Sweeney, G. P. 1987. Innovation, entrepreneurs and regional development. London: Frances Pinter.

Tewari Meenu, 1998. "Intersectoral linkages and the role of the state in shaping the conditions of industrial accu- mulation: a study of Ludhiana's manufacturing industry". World Development, 26, 8, 1387-1411.

Thompson, G. et al. eds. 1991. Markets, hierarchies and networks. The coordination of social life. London: Sage $\mathrm{Pu}-$ blications.

Trigilia, C. 1989. "Small firm development and political subcultures in Italy”. En: Goodman, E. \& Bamford, J. eds. 1989. Small firms and industrial districts in Italy. London: Routledge. Pp. 174-197.

Uribe-Echevarría, F. 1996. "Reestructuración económica y desigualdades interregionales. El caso de Chile". Revista EURE, 22, 11-38.

Van Dijk, M. P. 1994. Technological dynamism in industrial districts: an alternative approach to industrialisation in developing countries. New York/ Geneva: UNCTAD.

Van Dijk, M. P. 1994. "Industrial districts and urban economic development". Third World Planning Review, 15, 2 175-187.

Visser, E. J. 1996. Local sources of competitiveness - Spatial clustering and organisational dynamics in smallscale clothing in Lima, Peru. Amsterdam: University of Amsterdam. Ph. D. thesis.

Whitley, R. 1992. "Societies, firms and markets: the social structuring of business systems". En: Whitley, R. ed. 1992. European business systems: firms and markets in their national context. London: Sage. Pp 5-45.

Williams, K. Cutler, T., Williams, J. \& Haslam, C. 1987. "The end of mass production?" Economy and Society, 16, 3, 405-439.

Young, R. C. et al. 1994. Flexibility in small manufacturing firms and regional industrial formations. Regional Studies, 28, 1, 27-38.

Young, S., Hood, N. and Peters E. 1994. "Multinational enterprises and regio- 
Teorías de desarrollo industrial regional y políticas de segunda y tercera generación

nale economic development”. Regional Studies, 28, 7, 657-677.

Young Whee Rhee \& Soukirm C. 1989. "Small trading companies and a successful export response: lessons from Hong Kong”. Washington: World Bank. Industry \& Energy Department
Working Papers. Industry Series $\mathrm{Pa}-$ per no. 16.

Zeitlin, J. 1992. "Industrial districts and local economic regeneration: overview and comment”. En: Pyke, F. \& Segenberger, W. comps. Industrial districts and local economic regeneration. Ginebra: IILS. 